\title{
LA RESPONSABILIDAD CIVIL DEL CONCESIONARIO DE OBRAS VIALES Y SU FUNDAMENTO EN LA OBLIGACIÓN DE SEGURIDAD RESPECTO DE LOS USUARIOS EN EL DERECHO CHILENO*
}

["The Civil Liability of Road Works Concessionaires and its Grounds on the Safety Obligation to the user in the Chilean Law"]

\author{
José Luis Diez SCHWERTER ${ }^{* *}$ \\ Universidad de Concepción, Chile
}

\section{RESUMEN}

Este trabajo analiza el reconocimiento y aplicación que tiene en Chile la obligación del concesionario de obras públicas viales de garantizar la seguridad de los usuarios en la utilización de las obras concesionadas, como fundamento de su responsabilidad civil. Verificando luego que a esta obligación se le ha dado un alcance homogéneo frente a hipótesis dañosas similares, se concluye destacando el acercamiento importante que genera entre los distintos regímenes de respon-

\section{Abstract}

This paper examines the recognition and enforcement of the obligation of the road work concessionaire to ensure the safety of users in the use of road concessions as basis of civil liability in the Chilean law. Noting then that this obligation has been given a homogeneous scope facing similar hypothesis of harm, it is concluded highlighting the important approach that is generated between the different types of civil liability regimes

* Este trabajo forma parte del proyecto de investigación FONDECYT (regular 2010) No 1100949 , titulado "Responsabilidad civil de las concesionarias de autopistas por daños causados a usuarios y al medio ambiente con motivo de la ejecución o explotación de la obra: análisis crítico de su funcionamiento y propuestas de racionalización”, del que el autor es el investigador responsable.

** Profesor de Derecho civil de la Facultad de Ciencias Jurídicas y Sociales de la Universidad de Concepción. Dirección postal: Facultad de Ciencias Jurídicas y Sociales, Universidad de Concepción, Barrio Universitario s/n, Casilla 160-C, Correo 3, Concepción, Chile. Correo electrónico: jdiez@udec.cl 
sabilidad civil en base a los cuales se ha accionado en la materia.

Palabras clave

Concesionario de obras viales- Obligación de seguridad - Responsabilidad Civil. based on which lawsuits have been resolved in this matter.

\section{KEYWORDS}

Road work concessionaire - safety obligation-Civil Liability.

RECibido el 11 de enero y ACEPTADo el 1 de marzo de 2012.

\section{EL MARCO REGULADOR \\ DE LAS CONCESIONES DE OBRAS PÚBLICAS EN CHILE}

Un significativo impacto ha tenido en Chile la utilización en las últimas dos décadas del sistema de concesión de obras públicas como forma de asociación público-privada ${ }^{1}$.

El origen de su actual regulación se encuentra en la Ley $\mathrm{N}^{\circ} 18.060$ de 11 de noviembre de 1981, la cual modificando la Ley $\mathrm{N}^{\circ} 15.840$ de 1964 , sobre: Organización y Atribuciones del Ministerio de Obras Públicas, permitió la ejecución, reparación o mantención de las “obras públicas fiscales" a través del régimen de concesiones ${ }^{2}$.

Según señaló el "Mensaje" presidencial de esta ley (de 28 de mayo de 1981), el sistema de concesiones consiste en "autorizar al sector privado para realizar proyectos de infraestructura por cuenta propia, sometido a una normativa aprobada por el Ministerio de Obras Públicas, concediéndole la explotación de dicho proyecto por un periodo preestablecido, al final del cual la obra pasará a formar parte del patrimonio público", de modo que dicho sistema tiene por finalidad posibilitar una "mayor cobertura con el mismo gasto social" toda vez que él "liberará al Estado de construir todas y cada una de las obras de servicio público del pais, permitiéndole de tal modo preocuparse prioritariamente de aquellos proyectos en que exista una importante diferencia entre los beneficios sociales y privados".

En la actualidad los principales textos normativos que rigen las concesiones de obras públicas en Chile son los siguientes:

i) El Decreto con fuerza de ley $N^{\circ} 850$ del Ministerio de Obras Públicas, de 12 de septiembre de 1997, publicado en el Diario Oficial de 25 de febrero

\footnotetext{
${ }^{1}$ Para la evolución normativa en la materia: IBARRA Coronado, Rafael, La ley de concesiones de obras públicas chilena en el tiempo, en International Law. Revista Colombiana de Derecho Internacional, 19 (2011), pp. 183-222.

${ }^{2}$ Según dispuso el nuevo artículo 52 introducido a la Ley $\mathrm{N}^{\circ} 15.840$.
} 
de 1998, que fijó el texto refundido, coordinado y sistematizado de la Ley $\mathrm{N}^{\circ} 15.840$, de 1964, y del Decreto con fuerza de ley $\mathrm{N}^{\circ} 206$, de 1960 , cuyo artículo 87 autoriza al Ministerio de Obras Públicas para ejecutar obras públicas mediante el sistema de concesiones, aludiendo luego (en su artículo 88) a la normativa específica que las regulará.

ii) El Decreto No 900 del Ministerio de Obras Públicas, de 31 de octubre de 1996, publicado en el Diario Oficial de 18 de diciembre de 1996, que fija el texto refundido, coordinado y sistematizado del Decreto con fuerza de ley No 164 del Ministerio de Obras Públicas, de 1991 (comúnmente llamado "Ley de Concesiones de obras públicas", a la que en este trabajo se aludirá con la abreviatura LCOP.); y

iii) El Reglamento del Decreto con fuerza de ley $\mathrm{N}^{\circ} 164$ del Ministerio de Obras Públicas, de 1991, modificado por las Leyes No 19.252 de 1993 y $\mathrm{N}^{\circ} 19.460$, de 1996, contenido en el Decreto $\mathrm{N}^{\circ} 956$ del Ministerio de Obras Públicas de 6 de octubre de 1996, publicado en el Diario Oficial de 20 de marzo de 1999 (comúnmente llamado "Reglamento de la Ley de Concesiones de obras públicas" [= RLCOP.]), el cual por mandato normativo forma "parte integrante de los contratos de concesión que celebre el Ministerio de Obras Públicas" en la materia (artículo $1^{\circ}$ inciso $1^{\circ}$ ).

A ellos se añaden los instrumentos regulatorios específicos aplicables a cada obra concesionada, dentro de los cuales destacamos, desde ya, las "Bases de Licitación" (que se dividen en "Bases Administrativas", "Bases Técnicas" y "Bases Económicas"), la "Oferta Técnica y Económica” presentada por el adjudicatario de la concesión en la forma aprobada por el Ministerio de Obras Públicas, los decretos supremos de adjudicación respectivos, el correspondiente contrato y el "Reglamento de Servicio de la Obra", entre otros.

Cabe destacar finalmente en este punto que el sistema de concesiones ha tenido un gran impacto en el desarrollo de nuestro país. Al efecto desde 1993 a 2010 fueron licitados 67 proyectos, con una inversión aproximada de 11.700 millones de dólares ${ }^{3}$; los que han tenido objetos tan variados como tramos de la ruta 5 , autopistas urbanas, rutas transversales, mantención vial, infraestructura para Transantiago, aeropuertos, ferrocarriles, embalses, infraestructura penitenciaria, infraestructura pública, infraestructura hospitalaria y espacios urbanos ${ }^{4}$. Para el período 2010-2014 se proyecta una inversión de

${ }^{3}$ Ibarra Coronado, Rafael, cit. (n. 1) p. 186. Para la evolución del sistema en nuestro país: Domper, María de la Luz, Concesiones de obras públicas: lo que hemos avanzado y cuánto ha ganado Chile, en LARroulet, Cristián - Domper, María de la Luz (coordinadores), Concesiones: agenda para el 2020 (Santiago, Libertad y Desarrollo, 2009), pp. 15-40.

${ }^{4} \mathrm{El}$ detalle de los proyectos y contratos concesionados, en etapa de precalificación, 
8.009 millones de dólares, suma que se eleva a 11.739 millones de dólares considerando los proyectos en estudio 5 .

\section{LA OBLIGACIÓN DE SEGURIDAD DEL CONCESIONARIO DE OBRAS VIALES RESPECTO DE LOS USUARIOS COMO FUNDAMENTO DE SU RESPONSABILIDAD CIVIL}

\section{Objetivo de la investigación.}

El objetivo de este estudio consiste en analizar el fundamento, contenido y aplicación que tiene en Chile la obligación del concesionario de obras viales de garantizar la seguridad de los usuarios en la utilización de las obras concesionadas como fundamento de la responsabilidad civil que le puede afectar.

Ante la escasa doctrina que existe sobre el particular en nuestro medio ${ }^{6}$,

licitados y los de iniciativa privada en página www.concesiones.cl de la Coordinación de Concesiones de Obras Públicas del Ministerio de Obras Públicas.

${ }^{5} \mathrm{Al}$ respecto véase documento titulado: Primer Programa de Concesiones 20102014, Ministerio de Obras Públicas, jueves 15 de julio de 2010. http://www. concesiones.cl/proyectos/Documents/Documentos\%20varios/programa_ concesiones_2010_2014.pdf. Sobre los diversos aspectos de la proyección del sistema: Domper Rodríguez, María de la Luz, cit. (n. 3), pp. 15-40.

${ }^{6}$ Los estudios en la materia son aun escasos en nuestro medio y los que existen se han centrado en el análisis de la naturaleza jurídica de la responsabilidad civil que le asiste a los concesionarios de obras viales o, en su caso, a la eventual responsabilidad estatal en este sistema, los que son así problemas diversos al que desarrollamos en este trabajo. Al respecto pueden verse: KLEnNer, Arturo, Indemnización de perjuicios por daños personales o patrimoniales en el tránsito en vias concesionadas (Santiago, Aremi, 2007); Diez SChwerter, José Luis, Reparación y prevención de daños derivados de deficiencias viales en Chile: Panorama normativo y jurisprudencial, en Revista de Derecho de la Universidad de Concepción, 221-222 (2007 [pero 2008]), pp. 71-98 = GuZMán BRIto, Alejandro (editor científico), Estudios de Derecho Civil (Santiago, LegalPublishing, 2008), III, pp. 816-843; RaвAт Celis, Fernando José, Responsabilidad civil de las sociedades concesionarias de obras públicas fiscales respecto del usuario de las mismas, en Estudios jurídicos en homenaje a los profesores Fernando Fueyo Laneri, Avelino León Hurtado, Francisco Merino Scheihing, Fernando Mujica Bezanilla, Hugo Rosende Subiabre (Santiago, Ediciones Universidad del Desarrollo, 2007), pp. 279-298; RomÁN Cordero, Cristián, Responsabilidad de la Administración del Estado y de su concesionario vial, frente al usuario lesionado, en Actas de las XXXV Jornadas Chilenas de Derecho Público. El derecho público chileno ante la globalización (Valparaíso, Edeval, 2006), II, pp. 233-243; RomÁn Cordero, Cristián, La responsabilidad del Estado por los daños sufridos por el usuario de una carretera concesionada, por inactividad administrativa en ejercicio de sus facultades de inspección y vigilancia, en FERNÁNDEZ RUIZ, JorgeSantiago Sánchez, Javier (coordinadores), Contencioso administrativo. Culturas y sistemas jurídicos comparados (México, 2007), p. 359, [consultable también en Internet 
este estudio estará centrado en analizar su reglamentación vigente y la aplicación que le han dado las ya numerosas sentencias referidas a esta temática, en aspectos tales como el fundamento y extensión de esta obligación, y su aplicación ante las hipótesis dañosas más comunes que han motivado el ejercicio de acciones indemnizatorias en la materia, sea por responsabilidad extracontractual de derecho común (en juicios civiles o como acciones civiles deducidas ante los Juzgados de Policía Local como derivadas de infracción a la Ley N ${ }^{\circ}$ 18.290: Del Tránsito), por falta de servicio o por responsabilidad contractual (en sede civil o ante los Juzgados de Policía Local como acciones civiles derivadas de infracción a la Ley de protección de los derechos de los consumidores); verificando finalmente si en estos regímenes el incumplimiento de la obligación de seguridad ha servido para dar por configurada, respectivamente, culpa aquiliana, falta de servicio o culpa contractual, lo que, de producirse, generaría un notable acercamiento operativo entre ellos.

2. La centralidad de los artículos 23 y 35 de la Ley de Concesiones y 62 del RLCOP.

A nivel legal la obligación de seguridad analizada tiene como principal fundamento lo dispuesto en el artículo 23 LCOP., el cual, tratando de los derechos y obligaciones del concesionario dentro del régimen jurídico durante la fase de explotación, le impone el deber de asegurar "la continuidad de la prestación del servicio" la cual "le obligará, especialmente", añade la norma, a "facilitarlo en condiciones de absoluta normalidad, suprimiendo las causas que originen molestias, incomodidades, inconvenientes o peligrosidad a los usuarios de las obras, salvo que la adopción de medidas que alteren la normalidad del servicio obedezcan a razones de seguridad o de urgente reparación" (artículo $23 \mathrm{~N}^{\circ} 2$ letra b).

Por otro lado, y en términos aun más amplios, el artículo 62 RCOP. dispone: "La sociedad concesionaria deberá adoptar, durante la concesión, todas las medidas para evitar daños a terceros y al personal que trabaja en la obra. Igualmente deberá tomar todas las precauciones para evitar daños a la propiedad de terceros y al medio ambiente durante la concesión de la obra".

en: www.bibliojuridica.org/libros/5/2445/19.pdf]; Viñuela HoJas, Mauricio, La concesión de obras públicas en Chile: ¿Privatización de la responsabilidad del Estado en la empresa concesionaria? en Cuadernos de Extensión Jurídica, 7 (Santiago, Universidad de los Andes, 2003), pp. 109-135; Viñuela Hojas, Mauricio, La responsabilidad por falta de servicio en el contexto del régimen de concesiones viales vigentes en Chile, en Ius Publicum, 7 (Santiago, Universidad San Tomás, 2001), pp. 35-55; y Águila Rojas, Enrique Adolfo, De la responsabilidad extracontractual por daños en las carreteras concesionadas Memoria de Prueba para optar al Grado de Licenciado en Ciencias Jurídicas, Universidad Bolivariana, (Santiago, 2006 [pero 2007]). 
Y ha sido considerando principalmente lo dispuesto en los mencionados preceptos que la jurisprudencia nacional concluye, pacíficamente, que el concesionario vial tiene la obligación de garantizar a los usuarios la seguridad en la utilización de las obras concesionadas ${ }^{7}$, la cual incluso ha sido calificada de "principal" en esa relación ${ }^{8}$ y propia de todo ente explotador de una actividad que "puede provocar riesgo a terceros", y cuyo reconocimiento legal se funda

${ }^{7}$ Así, entre muchas otras: sentencia de 29 de septiembre del 2006, dictada por

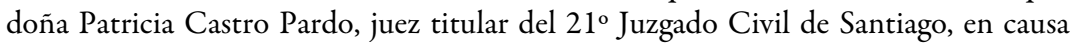
rol No C-1638-2005, caratulada "Moya Acevedo Ángel Gabriel y otros con Autopista del Maipo S.A.", donde se señala que la sociedad concesionaria tiene la obligación "de prevención de accidentes por medio de la mantención del bien concesionado"; Corte de Apelaciones de Santiago, sentencia de 9 de junio de 2009, rol No 9196-2006, caratulada "Moya Acevedo Ángel Gabriel y otros con Autopista del Maipo S.A.”, redacción del abogado integrante señor Enrique Pérez Levetzow, donde se dice que: "es obligación de la concesionaria otorgar seguridad a todos los usuarios que se sirvan del servicio ofrecido, para asi evitar que a estos se les produzcan daños con motivo del uso de tal vía concesionada"; sentencia de 31 de julio de 2009, dictada por don Javier Torres Vera, juez titular del $27^{\circ}$ Juzgado Civil de Santiago, en causa rol No C-10375-2004, caratulada "Bossay Pisano, Paula y Varas Boetsch, Miguel con Fisco de Chile y Sociedad Concesionaria Rutas del Pacífico", donde se estableció que el concesionario tiene un deber de cuidado, el que "se traduce finalmente en su obligación de otorgar a sus usuarios, quienes pagan un derecho, no sólo por el uso y la rapidez de desplazamiento en la vía o el servicio en ruta ofrecido, sino por la seguridad del trayecto"; sentencia de 14 de octubre de 2009, dictada por doña Inelie Durán Madina, juez titular del $2^{\circ}$ Juzgado Civil de Santiago, en causa rol No C-17544-2007, caratulada "Gómez Zúñiga Julio con Autopista del Sol y Fisco de Chile”, en la cual en base a lo dispuesto en la letra a) del No 2 del artículo 23 de la "Ley de Concesiones de Obras Públicas" se da por establecida la "obligación de seguridad que contrae el concesionario respecto de los usuarios de la obra pública”; Corte de Apelaciones de Santiago, sentencia de 30 de marzo de 2010, rol No 3311-2009, caratulada "González Vergara Jorge con Ruta 5 Tramo Talca-Chillán”, redacción del abogado integrante señor Francisco Tapia Guerrero, donde se señala que el concesionario tiene la obligación de "otorgar seguridad a los usuarios que se sirvan de la concesión"; sentencia de 2 de octubre de 2010, dictada por don Pablo Gabriel Yánez Gómez, juez titular del Juzgado de Letras y Garantía de La Unión, en causa rol No C-155-2008, caratulada "Ramírez M. Juan y otro con Ruta de Los Ríos Sociedad Concesionaria S.A.”, donde se expresa que a cambio del peaje "el concesionario debe permitir el tránsito y garantizar las debidas condiciones de seguridad".

${ }^{8}$ Sentencia de 30 de abril de 2009, dictada por doña María Paula Merino Verdugo, juez titular del $4^{\circ}$ Juzgado Civil de Santiago, en causa rol № C-5148-2006, caratulada "González Vergara Jorge con Ruta 5 Tramo Talca Chillán”. En el mismo sentido: Corte de Apelaciones de Valparaíso, sentencia de 16 de septiembre de 2010, rol No 77-2010, caratulada "Avilés Sepúlveda María con Sociedad Concesionaria Rutas del Pacífico S.A.”, redacción del abogado integrante señor Juan Carlos Cárcamo Olmos, donde se afirma que este es uno de los "deberes de cuidado elementales" del concesionario respecto del usuario.

${ }^{9}$ Sentencia de 21 de abril de 2006, dictada por doña Alba Eliana Valdés González, 
en la "intensidad y probabilidad del daño, el costo de evitar los accidentes y el tipo de relación entre el autor del daño y la victima"10.

Como recuerda la Corte Suprema, las "exigencias de normalidad del servicio" imponen que las vías deben estar "despejadas, libres de toda perturbación $y$ dando estricto cumplimiento a las normas de seguridad"11, obligación que además ha sido entendida como constante y permanente, pues existiendo "el derecho a cobrar tal tarifa por cada distancia usada, kilómetro o metro de camino de que se trate, es equivalente la obligación de mantener en correcto estado similar distancia"12.

Como corolario de lo anterior, tanto la "Ley de concesiones de obras públicas" como el "Reglamento" reconocen que el concesionario tiene la obligación de responder por los daños, de cualquier naturaleza, que con motivo de la ejecución de la obra o de su explotación hayan podido sufrir los usuarios o terceros, a menos que sean exclusivamente imputables a medidas impuestas por el Ministerio de Obras Públicas, después de haber sido adjudicado el contrato (artículos 35 LCOP..$^{13}$ y $62 \mathrm{~N}^{\circ} 1$ RLCOP..${ }^{14}$ ); debiendo tenerse presente que el "Reglamento" asegura incluso la solvencia económica de las concesionarias ante eventuales acciones indemnizatorias adversas en esta materia al obligarlas a "tomar pólizas de seguro que cubran la responsabilidad civil por daños a terceros" (artículo 36).

Juez Subrogante del 20 Juzgado Civil de Santiago, en causa rol No C-7233-2005, caratulada "Donoso Solís Eduardo Enrique con Sociedad Concesionaria Autopista Vespucio Sur S.A."

${ }^{10}$ Sentencia de 25 de julio de 2006, dictada por doña Jenny Book Reyes, juez titular del $7^{\circ}$ Juzgado Civil de Santiago, en causa rol No 3421-2003, caratulada "Borjes Muñoz, María Teresa con Sociedad Concesionaria Autopista del Sol S.A.”, transcrita en KLENNER, Arturo, cit. (n. 6), pp. 215-234.

${ }^{11}$ Corte Suprema, sentencia de 17 de agosto de 2011, rol № 6370-2009, caratulada "Bravo Cisternas Freddy con Sociedad Concesionaria Autopista del Aconcagua S.A", redacción de la abogado integrante señora Maricruz Gómez de la Torre Vargas.

${ }^{12}$ Corte de Apelaciones de Santiago, sentencia de 5 de noviembre de 2010, rol No 8162-2009, caratulada “Gómez Zúniga Julio con Autopista del Sol y Fisco de Chile”, redacción del abogado integrante señor Enrique Pérez Levetzow.

${ }^{13}$ Artículo 35: "El concesionario responderá de los daños, de cualquier naturaleza, que con motivo de la ejecución de la obra o de la explotación de la misma se ocasionaren a terceros, a menos que sean exclusivamente imputables a medidas impuestas por el Ministerio de Obras Públicas, después de haber sido adjudicado el contrato".

${ }^{14}$ Artículo 62: "Daños a terceros. [...] 2.- La sociedad concesionaria será la única responsable de todo daño, de cualquier naturaleza, que con motivo de la ejecución de la obra $y$ de su explotación se cause a terceros, al personal de la obra, a la propiedad de terceros o al medio ambiente, a menos que el daño sea exclusivamente imputable a medidas impuestas por el MOP después de la publicación del decreto supremo de adjudicación en el Diario Oficial'. 


\section{La normativa complementaria.}

A lo dispuesto en los preceptos antes mencionados se añade el deber que tiene el concesionario de obras viales de cumplir una extensa normativa, de diversa jerarquía, que viene a concretar y/o complementar la obligación de seguridad analizada, de lo cual incluso han dado cuenta muchas sentencias en este ámbito.

$\mathrm{Al}$ efecto, se pueden mencionar:

a) Exigencias legales propias del régimen de concesión. Como son, por ejemplo:

i) la obligación de "conservación y reparación de las obras entregadas en concesión" (artículo 18 inciso $1^{\circ}$ parte final del Decreto con fuerza de ley $\mathrm{N}^{\circ} 850$ de 25 de febrero de 1998 que fijó el texto refundido, coordinado y sistematizado de la Ley $\mathrm{N}^{\circ} 15.840$ de 1964 y el Decreto con fuerza de ley $\mathrm{N}^{\circ} 206$ de 1960).

ii) la "obligación de cumplir, durante toda la vigencia de la concesión, con los niveles de servicio, estándares técnicos o ambos, establecidos en las respectivas bases de licitación, para las diferentes etapas y condiciones de la concesión" (artículo $1^{\circ}$ inciso $2^{\circ}$ LCOP. introducido por la Ley $\mathrm{N}^{\circ} 20.410$ ).

iii) la obligación, explicitada para la fase de explotación, de "conservar las obras, sus accesos, señalización y servicios en condiciones normales de utilización" (artículo $23 \mathrm{~N}^{\circ} 1$ de la LCOP.).

iv) la obligación, explicitada también para la fase de explotación, de prestar el servicio "ininterrumpidamente, salvo situaciones excepcionales, debidas a caso fortuito o fuerza mayor" (artículo $23 \mathrm{~N}^{\circ} 2$ letra b) LCOP.).

v) la obligación de "velarpor la perfecta aplicación de las normas y reglamentos sobre uso y conservación de las obras concedidas" (artículo 24 LCOP.).

b) Exigencias establecidas en el RLCOP. Entre las cuales se pueden mencionar:

i) la obligación de "conservación de la obra en óptimas condiciones de uso", según lo exigido por las bases de licitación (artículos $1^{\circ} \mathrm{N}^{\circ} 3$ letra b y 54 letra b) del RLCOP.).

ii) la obligación de contar con un "Reglamento de Servicio de la Obra" el cual regirá el "uso de la obra y los servicios que prestará el concesionario", y en el que, junto a "todas las normas derivadas de las bases de licitación y oferta técnica" se regularán, entre otras materias, las "medidas de cuidado de la obra, seguridad y vigilancia", las "medidas de mantención y aseo de las distintas instalaciones", las "medidas orientadas a detectar y solucionar los problemas de accidentes, congestión o de cualquier otra naturaleza que se produzcan en el camino, respecto de las concesiones viales", la "enumeración de los derechos y obligaciones de los usuarios por el uso de los servicios prestados", las "normas de utilización de los servicios obligatorios que establezcan las bases de licitación 
$y$ de los servicios complementarios", y los "estándares de operación, calidad y gestión para la prestación de los servicios" (todo ello en el artículo 57 del RLCOP) $)^{15}$.

Cabe destacar que la importancia de este instrumento es tal que el Ministerio de Obras Públicas no puede dar la autorización de puesta en servicio provisoria de la concesión si no se le ha aprobado previamente.

iii) "en el plazo que dispongan las bases de licitación, contado desde la ocupación material de uno o más terrenos correspondientes a la concesión", la obligación para el concesionario de "cercarlo bajo la supervisión del MOP en la forma que indiquen las bases de licitación” (artículo $60 \mathrm{~N}^{\circ} 1$ del RLCOP.).

$i v$ ) la obligación de "vigilancia de los terrenos y bienes afectos a la concesión" y que afecta al concesionario "a partir de la ocupación y hasta la extinción de la concesión" debiendo al efecto cuidar "especialmente de mantenerlos libres de ocupantes, de no permitir alteraciones de sus límites y de no admitir depósito de material ajeno a la concesión" (artículo 60 №2 del RLCOP.).

v) la obligación de otorgar el servicio "sin discriminación de ninguna especie a los usuarios, siempre que éstos cumplan con las condiciones del servicio y con el pago de las tarifas autorizadas en el contrato de concesión" (artículo $61 \mathrm{~N}^{\circ} 1$ del RLCOP).

c) Exigencias contenidas en los instrumentos normativos particulares de cada obra concesionada. Dentro de las cuales se encuentran:

i) las establecidas en las respectivas "Bases de Licitación", en las cuales, junto con reiterar las obligaciones de seguridad y de prevención antes referidas, se explicitan también exigencias específicas según sea la naturaleza de la obra respectiva ${ }^{16}$.

${ }^{15}$ Así, por ejemplo, analizando este Reglamento: sentencia de 31 de julio de 2009, dictada por don Javier Torres Vera, juez titular del $27^{\circ}$ Juzgado Civil de Santiago, en causa rol No C-10375-2004, caratulada "Bossay Pisano, Paula y Varas Boetsch, Miguel con Fisco de Chile y Sociedad Concesionaria Rutas del Pacífico”, en particular el cumplimiento de las medidas impuestas por el "Reglamento de Servicio de la obra: Concesión Internacional Interconexión Vial Santiago Valparaíso Viña del Mar”, en su acápite 3.2.3. referido específicamente a la "Obligación de velar por la seguridad de los usuarios".

${ }^{16}$ Analizando en este tipo de pleitos lo dispuesto en las Bases de licitación, véanse, entre muchas otras: sentencia de 25 de julio de 2006, dictada por doña Jenny Book Reyes, juez titular del $7^{\circ}$ Juzgado Civil de Santiago, en causa rol No 3421-2003, caratulada "Borjes Muñoz, María Teresa con Sociedad Concesionaria Autopista del Sol S.A.", transcrita en KlenNer, Arturo, cit. (n. 6), pp. 215-234, indicándose que "las disposiciones contenidas en las bases de licitación, citadas en los considerandos noveno y décimo, vienen a reglamentar las medidas de seguridad y control que la concesionaria debe implementar para precaver daños a terceros, constituyendo parte del marco legislativo que 
Así, por ejemplo, en las "Bases Administrativas” aparece reiterado frecuentemente que la sociedad concesionaria está obligada a mantener las obras en explotación en "condiciones normales de servicio"17, así como el ser "siempre responsable del cumplimiento cabal, íntegro y oportuno del contrato de concesión, de la correcta ejecución de los proyectos y de las obras, sin perjuicio de las funciones de dirección y de control que correspondan al Ministerio de Obras Públicas"18 y "la única responsable de todo daño o perjuicio", sea que se cause a terceros, al personal de la obra, a la propiedad de terceros o al medioambiente, a menos que estos daños sean exclusivamente imputables a medidas impuestas por el Ministerio de Obras Públicas, después de haber sido adjudicado el contrato. ${ }^{19}$

Por su parte, en numerosas "Bases Técnicas" aparecen referencias a obligaciones relativas a la Seguridad Vial y Señalización, las que se traducen en la ejecución de "Planes de Seguridad" respecto de los usuarios y de las propias instalaciones; de "Planes de Señalización” y "Medidas de Seguridad y Control” en general ${ }^{20}$.

regula el desarrollo de su actividady, por ende, un deber de cuidado establecido en la ley"; Corte de Apelaciones de Santiago, sentencia de 9 de noviembre de 2010, rol No 65232009, caratulada "Bossay Pisano, Paula y Varas Boetsch, Miguel con Fisco de Chile y Sociedad Concesionaria Rutas del Pacífico”, redacción de la Ministro señora Dobra Lusic Nadal, en la cual se señala que "de estos cuerpos normativos, así como de las Bases de licitación resulta clara la obligación asumida por la Concesionaria de realizar todas las obras necesarias y adoptar todas las medidas para evitar daños a terceros, en término de brindar a los usuarios los estándares prudentes y convenientes de seguridad."

${ }^{17}$ En tal sentido, por ejemplo: "Bases de licitación de la concesión Ruta 5, Tramo La Serena-Vallenar”, del Ministerio de Obras Públicas, 2009 (cláusula 2.4.6.2); “Concesión Ruta 5, Tramo Pto. Montt-Pargua”, del Ministerio de Obras Públicas, 2009 (cláusula 2.5.4.3); "Concesión Ruta de la Madera”, del Ministerio de Obras Públicas, 1997 (cláusula 1.5.41); "Concesión Ruta 60 Ch”, del Ministerio de Obras Públicas, 2001 (cláusula 1.8.14); entre otras.

${ }^{18}$ Así, por ejemplo, entre otras: "Bases de licitación, Concesión Ruta 5, Tramo La Serena-Vallenar”, del Ministerio de Obras Públicas, 2009 (cláusula 1.7.7.2.); "Bases de licitación, Concesión Autopistas Región de Antofagasta”, MOP 2009 (cláusula 1.7.7.2.); "Concesión Acceso Norte a Concepción", del Ministerio de Obras Públicas, 1994 (cláusula 1.7.8.2).

${ }^{19}$ Así, por ejemplo, entre otras: "Bases de licitación de la Concesión de la Ruta 60 Ch", del Ministerio de Obras Públicas, 2001 (cláusula 1.8.14); "Concesión de la Ruta Concepción-Cabrero”, del Ministerio de Obras Públicas, 2009 (cláusula 1.8.15); "Concesión de la Ruta 5, Tramo La Serena-Vallenar", del Ministerio de Obras Públicas, 2009 (cláusula 1.8.14); "Concesión de la Ruta 5, Tramo Talca-Acceso sur Santiago”, del Ministerio de Obras Públicas, 1998 (cláusula 8.5.3.5); y "Concesión Santiago-Melipilla, Camino de la Fruta”, del Ministerio de Obras Públicas, 2010 (cláusula 1.8.14).

${ }^{20}$ Así, por ejemplo, entre otras: "Bases de licitación de la concesión de la Ruta 5, Tramo La Serena-Vallenar”, del Ministerio de Obras Públicas, 2009 (cláusula 2.4.6); 
ii) las establecidas en los respectivos "decretos de adjudicación”, en los que, junto con fijar las funciones incorporadas al contrato de concesión respectivo $^{21}$ y la normativa que los regula ${ }^{22}$, deben explicitarse también las obligaciones y derechos del adjudicatario ${ }^{23}$.

iii) las establecidas en el respectivo "Reglamento de servicio de la obra".

iv) las establecidas en los diversos Manuales de procedimiento que en cada obra concesionada se puedan establecer para enfrentar determinadas

"Concesión Santiago-Melipilla, Camino de la Fruta", del Ministerio de Obras Públicas, 2010 (cláusula 2.4.4.2); "Concesión de la Ruta 5, Talca-Acceso sur Santiago", del Ministerio de Obras Públicas, 1998 (cláusula 2.5.3.2); "Concesión de la Ruta 60 Ch", del Ministerio de Obras Públicas, 2001 (cláusula 2.4.3.5); y "Concesión de la Ruta Concepción-Cabrero”, del Ministerio de Obras Públicas, 2009 (cláusula 2.4.4.2).

${ }^{21}$ Como la ejecución o construcción, conservación y explotación.

${ }^{22}$ Así, por ejemplo, el Decreto $N^{\circ} 225$ del Ministerio de Obras Públicas, de junio de 2011, que adjudica "Concesión de obra fiscal alternativas de acceso a Iquique", en el cual se señala: "11.- De acuerdo con lo establecido en el artículo 2.2.1 de las Bases de licitación, los proyectos de ingeniería en detalle que debe confeccionar la Soc. Concesionaria deberá cumplir los estándares técnicos contenidos en las Bases de licitación y Estudios Referenciales, asi como también en la normativa vigente, los instructivos de los Departamentos de Gestión Vial, de Estudios Viales, de puentes, y de seguridad vial de la Dirección de Vialidad, debiendo considerar, entre otros, los siguientes documentos: Manual de Carreteras de la Dirección de Vialidad del MOP, versión Marzo 2008, incluidas todas sus actualizaciones al momento de realizar el proyecto de ingeniería definitivo; Normas oficiales del Instituto Nacional de Normalización (INN);M Manual de Señalización del Tránsito del Ministerio de Transportes y Telecomunicaciones (MTT). Especificamente Cap. I, introducción', Cap. 2, 'señales verticales' (agosto 2000), Cap. 3, 'Demarcaciones' (enero 2001); Cap. 4 'semáforos' (junio 1989); Cap. 5, 'señalización transitoria y medidas de seguridad para trabajos en la vía' (enero 2003); Cap. 6, 'Facilidades explícitas para peatones y ciclistas' (febrero 2004), y sus modificaciones o nuevas versiones, en especial Cap. 4, 7, 8 y 9; Guía AASHTO para diseño estructural de pavimentos, en su versión vigente; Normas de la Superintendencia de Electricidad y Combustibles (SEC); Esquema operacional de postes SOS de la Coordinación de Concesiones del del Ministerio de Obras Públicas; Ley y Ordenanza General de Urbanismo y Construcciones y los instrumentos de planificación territorial vigentes (Planes Reguladores Comunales e Intercomunales) correspondientes al territorio de emplazamiento del proyecto; las Bases de licitación./ Además el MOP podrá, durante el desarrollo de los estudios, solicitar al Concesionario precisar, acotar y/o corregir la información de estos, con el objetivo de que se cumplan las condiciones de suficiencia para definir adecuadamente las otras objeto de la Concesión, debiendo el concesionario desarrollar a su entero cargo y costo los estudios que sean necesarios"-

${ }^{23} \mathrm{Al}$ efecto es común encontrar que en ellos se señale que "los derechos y obligaciones del concesionario son los establecidos en los Cuerpos Legales citados precedentemente, en las Bases de licitación, en sus [eventuales] Circulares Aclaratorias y en la Oferta Técnica y Económica presentada por el Licitante Adjudicatario" y añadiéndose que el concesionario debe "construir, conservar y explotar las obras indicadas en las Bases de licitación, en la forma, modo y plazos señalados en dicho instrumento". 
contingencias o actividades (como, por ejemplo, "Manuales de emergencias", "Manuales de patrullaje", entre otros).

Cabe destacar que si bien todos estos instrumentos forman parte de la relación contractual que liga al Estado con el concesionario, ellos son aplicados pacíficamente en los juicios sobre responsabilidad civil seguidos por los usuarios en la materia ${ }^{24}$.

d) Exigencias contenidas en la normativa que regula el diseño, señalización y seguridad vial. Dentro de las cuales podemos mencionar:

i) las contenidas en el "Manual de carreteras" 25 , y cuya exigibilidad se desprende de lo dispuesto en los artículos $23 \mathrm{~N}^{\circ} 1$ y 24 LCOP., así como

${ }^{24}$ Aunque se exige que se incorporen legalmente al proceso: así sentencia de 26 de octubre de 2004, dictada por doña Carola Rivas Vargas, juez titular del $12^{\circ}$ Juzgado Civil de Santiago, en causa rol № C-2695-2003, caratulada "Concha Soffia, Cristián con Sociedad Concesionaria Rutas del Pacífico S.A.”, transcrita en KLENNER, Arturo, cit. (n. 6), pp. 174-181, donde atendiendo a que el artículo 21 LCOP. dispone que las funciones que debe cumplir el concesionario son aquellas "incorporadas al contrato de concesión", se concluye que "era menester acreditar en autos, con el respectivo contrato o Decreto, asi como con las Bases de la licitación, que se entienden incorporadas, cuáles eran en forma concreta y determinada estas funciones, para con ello poder concluir la existencia o no de su omisión o incumplimiento parcial o total". En el mismo sentido: Corte de Apelaciones de Concepción, sentencia de 18 de marzo de 2011, rol No 1420-2010, caratulada "Muñoz Cuevas Alejandro Marcelo y otra con Camino de la Madera Sociedad Concesionaria S.A.”, redacción del abogado integrante señor Hugo Tapia Elorza, donde se señala que: "ninguna prueba se rindió en el proceso para demostrar con exactitud cuáles son las obligaciones especificas que asumió la concesionaria con motivo de la explotación de la ruta denominada "Camino a la Madera" y haber determinado de este modo si incurrió en algún tipo de incumplimiento". En todo caso, el examen de "Bases de licitación", los "Decretos de Adjudicación" y los "Reglamentos de Servicio de las obras concesionadas" están disponibles electrónicamente en la página de la Dirección de Concesiones del Ministerio de Obras Pública (www.concesiones.cl).

${ }^{25} \mathrm{El}$ "Manual de carreteras" está compuesto de nueve volúmenes, de los cuales especial importancia tendrán en esta materia el Volumen $\mathrm{N}^{\circ} 3$ : "Instrucciones y criterios de Diseño", el Volumen $\mathrm{N}^{\circ}$ 6: "Seguridad Vial” y el Volumen $\mathrm{N}^{\circ}$ 7: "Mantenimiento Vial”. Al respecto, por ejemplo, la Corte Suprema ha señalado que lo dispuesto en el artículo 23 LCOP.: "guarda correspondencia con la pauta normativa y técnica entregada por la Dirección de Vialidad en el Manual de Carreteras, que establece en el punto 3.802 .3 que 'Sea en curva o en recta se debe considerar la instalación de defensas; si existe una posibilidad de accidente o si la altura del terraplén o en el terreno abrupto provocan una sensación de inseguridad en el conductor'. Destaca: 'Los sectores que pueden presentar condiciones adversas de neblina, hielo o nieve o sectores de camino con tránsito de alta velocidad o elevado volumen, justifican la consideración de defensas". Corte Suprema, sentencia de 28 de enero 2010, rol No 6919-2008, caratulada "Canales Valenzuela María con Ruta 5 Tramo Talca Chillán S.A.”, redacción a cargo del Ministro señor Héctor Carreño. 
en las recurrentes remisiones contenidas a su respecto en distintas "Bases de licitación"26.

ii) las contenidas en el "Manual de señalización de tránsito" 27 y cuya exigibilidad emana, primeramente, de lo dispuesto en los artículos $23 \mathrm{~N}^{\circ} 1$ y 24

${ }^{26}$ Así, por ejemplo, aparecen remisiones al "Manual de carreteras” en "Bases de licitación de la Ruta 66-Camino de la fruta”, del Ministerio de Obras Públicas, 2010, pp. 20, 113, 162 ss., 222; "Bases de licitación de la Red Vial Litoral Central”, del Ministerio de Obras Públicas, 2000, pp. 11, 47, 70, 125, 137, 139; "Bases de licitación del Camino Internacional Ruta 60 Ch”, del Ministerio de Obras Públicas, 2001, pp. 13, 74, 123, 124, 127, 143, 154; "Bases de licitación de la concesión vial autopistas de la región de Antofagasta”, del Ministerio de Obras Públicas, 2009, pp. 13, 106, 110, 151-156, 159, 166-170, 179, 199, 201, 221, 229, 235, 240; "Bases de licitación de la concesión internacional Sistema Norte-Sur”, del Ministerio de Obras Públicas, 2000, pp. 11, 15, 18, 76, 136-142, 167, 206, 207; "Bases de licitación de la concesión internacional Sistema Oriente-Poniente”, del Ministerio de Obras Públicas, s/d, pp. 7, 10, 14, 66, 118-121, 180, 181, 215; "Bases de licitación de la concesión Sistema Américo Vespucio Sur, Ruta 78”, del Ministerio de Obras Públicas, 2001, pp. 13, 17, 70, 125, 126, 128, 152, 186, 187, 195; “Bases de licitación de la concesión Ruta 5, tramo Temuco-Río Bueno”, del Ministerio de Obras Públicas, 1997, pp. 7, 9, 36, 86, 90, 91, 95, 98; entre otras (todas ellas consultadas en www.concesiones.cl).

${ }^{27}$ Así, por ejemplo, en sentencia de 29 de septiembre de 2005, dictada por doña Rocío Pérez Gamboa, Juez Suplente del $25^{\circ}$ Juzgado Civil de Santiago, en causa rol N ${ }^{\circ}$ 5778-2002, caratulada "Calderón Reyes, Elisa con Ruta del Pacífico S.A.", transcrita en KLenner, Arturo, cit. (n. 6), pp. 181-205, donde se analiza el cumplimiento a lo dispuesto en el Decreto Supremo N 63 del Ministerio de Transporte y Telecomunicaciones, y su anexo de 15 de mayo de 1986, sobre Modificación al Manual de Normas Técnicas para la Señalización, Control y Regulación del Tránsito en Vías donde se realizan Trabajos. Sobre la naturaleza del Manual de Señalización de Tránsito: sentencia de 25 de enero de 1988, dictada por el juez titular don Sergio José Sánchez J., y confirmada por la Corte de Apelaciones de Santiago, en sentencia de 26 de abril de 1989 y por la Corte Suprema en sentencia de 19 de julio de 1990, todas en Gaceta Jurídica 121 (Santiago, 1990), p. 58 ss.

En todo caso, y como bien ha precisado nuestra Corte Suprema, debe tenerse en cuenta además que "una señalización especifica puede ser perfectamente adecuada en un sector o intersección determinada, pero completamente insuficiente e ineficiente en otros. Ese grado de adecuación de la señalización está dado por los factores de riesgo detectables en cada una de esas zonas, los que a su vez se relacionan en forma directa y obvia, a lo menos con el fujo vehicular y peatonal que exista en el lugar. Más aun, en ciertas zonas especificas el grado de riesgo se relaciona con la clase de peatones que hay en el sector, como tipicamente ocurre en zonas de colegios o escuelas", todo ello pues en definitiva "la voz 'adecuadamente' se asocia con la idea de protección eficiente y razonable dado el grado de riesgo implícito para los bienes jurídicos" vida y salud individual de las personas. Corte Suprema, sentencia de 13 de septiembre de 1999, sentencia de reemplazo, en RDJ. 96 (Santiago, 1999), $2^{\text {a }}$ parte, sección $4^{\text {a }}$, pp. 236-242). 
$\mathrm{LCOP}^{28}{ }^{28}$, sin perjuicio de las recurrentes remisiones que a él se le hacen en las "Bases de licitación" ${ }^{29}$ y en los "Reglamentos de servicio de las obras"30.

e) Las exigencias que imponen instructivos o normas técnicas emitidas por la Dirección de Vialidad, muchas veces referidas directamente en los "Decretos de adjudicación"31.

${ }^{28}$ Así, por ejemplo: Corte de Apelaciones de Santiago, en sentencia de 30 de marzo de 2010, rol No 3311-2009, caratulada "González Vergara Jorge con Ruta 5 Tramo Talca-Chillán”, redacción del abogado integrante señor Francisco Tapia Guerrero.

${ }^{29}$ Así, por ejemplo, hay remisiones al "Manual de señalización de tránsito" en "Bases de licitación de la Ruta 66-Camino de la fruta", del Ministerio de Obras Públicas, 2010, p. 163, 185, 242, 274; "Bases de licitación de la Red Vial Litoral Central", del Ministerio de Obras Públicas, 2000, p. 134, 136, 143, 160; "Bases de licitación de la Camino Internacional Ruta 60 Ch”, del Ministerio de Obras Públicas, 2001, p. 123, 133, 156; "Bases de licitación de la concesión vial autopistas de la región de Antofagasta”, del Ministerio de Obras Públicas, 2009, p. 152, 202, 235, 240, 241; "Bases de licitación de la concesión internacional Sistema Norte-Sur”, del Ministerio de Obras Públicas, 2000, p. 136, 145, 164, 247; "Bases de licitación de la concesión internacional Sistema Oriente-Poniente”, del Ministerio de Obras Públicas, s/d, p. 118, 141, 143, 144, 214; "Bases de licitación de la concesión Sistema Américo Vespucio Sur, Ruta 78”, del Ministerio de Obras Públicas, 2001, p. 125, 133, 148, 224; “Bases de licitación de la concesión Ruta 5, tramo Temuco-Río Bueno”, del Ministerio de Obras Públicas, 1997, p. 78; "Bases de licitación de la concesión Ruta 5, tramo Talca-Chillán”, del Ministerio de Obras Públicas, s/d, p. 64; "Bases de licitación de la concesión Ruta 5, tramo Santiago-Talca y acceso sur a Santiago”, del Ministerio de Obras Públicas, 1998, p. 142; "Bases de licitación de la concesión Ruta 5, tramo Santiago-Los Vilos", del Ministerio de Obras Públicas, 1996, p. 75; "Bases de licitación de la concesión Ruta 5, tramo Río Bueno-Pto. Montt", del Ministerio de Obras Públicas, 1997, p. 102; "Bases de licitación de la concesión Ruta 5, tramo Pto. Montt-Pargua”, del Ministerio de Obras Públicas, 2009, p. 143, 169, 179, 219; "Bases de licitación de la concesión Ruta 5, tramo Los Vilos-La Serena”, del Ministerio de Obras Públicas, 1996, p. 75; "Bases de licitación de la concesión Ruta 5, tramo Collipulli-Temuco", del Ministerio de Obras Públicas, 1997, p. 104; "Bases de licitación de la concesión Ruta 5, tramo Chillán-Collipulli", del Ministerio de Obras Públicas, 1996, p. 87; "Bases de licitación de la concesión Ruta 5, tramo Vallenar-Caldera”, del Ministerio de Obras Públicas, 2008, p. 148, 163, 194, 226, 230; entre otras (todas ellas consultadas en www.concesiones.cl).

${ }^{30}$ Así, por ejemplo: "Reglamento de Servicio Concesión Vial Avenida Vespucio Sur, Soc. Concesionaria Vespucio Sur S.A.”, Santiago, 2005, 2.6.8. (v. tránsito, 3.6.1.); en el mismo sentido, "Reglamento de Servicio Concesión sistema Norte-Sur, Soc. Concesionaria Autopista Central S.A.”, Santiago, 2004, Cap. VI; "Reglamento de Servicio Concesión 'obras acceso Aeropuerto Arturo Merino Benítez, Soc. Concesionaria Autopista del Itata S.A.”, Santiago, s/d, 7.2.

${ }^{31}$ Así, por ejemplo, Decreto $\mathrm{N}^{\circ} 112$ del Ministerio de Obras Públicas, junio de 1993, en que se adjudica Concesión "Tunel El Melón", No 3 donde se señala que "Se entiende incorporado al Contrato de Concesión y por ende a este decreto las disposiciones pertinentes de los siguientes cuerpos legales: [...] d) Pautas y normas técnicas vigentes de la Dirección de Vialidad]. En el mismo sentido: Decreto $\mathrm{N}^{\circ} 322$ del Ministerio de Obras 
f) La exigencias contempladas en las "Normas oficiales chilenas" relacionadas con la materia ${ }^{32}$, a las cuales se suelen remitir con frecuencia las respectivas Bases de Licitación ${ }^{33}$ (en especial a la "Norma

Públicas, de junio de 1995, que adjudica concesión de obra pública fiscal "Autopista Santiago San Antonio", No 3; Decreto $\mathrm{N}^{\circ} 387$, julio de 1995, que adjudica concesión de obra pública fiscal "Camino Nogales-Puchuncaví", No 3; Decreto $\mathrm{N}^{\circ} 133$ del Ministerio de Obras Públicas, abril de 2004, que adjudica concesión de obra pública fiscal "Camino de la Madera", № 3; Decreto $\mathrm{N}^{\circ} 7$ del Ministerio de Obras Públicas, enero de 1995, que adjudica concesión de obra pública fiscal “Acceso Norte a Concepción”, No 3; Decreto $\mathrm{N}^{\circ} 1129$ del Ministerio de Obras Públicas, diciembre de 2004, que adjudica concesión de obra pública fiscal 'Concesión variante Vespucio-El Salto-Kennedy', No 6 , parte final.

${ }^{32}$ Así, por ejemplo, en un fallo se establece que: “la barrera frente a la cual chocó el demandante cumplió con las normativas técnicas al momento de su construcción (Manual de Carreteras del año 1974). Asi, los Manuales de Carreteras posteriores tienen un campo de aplicación restringido a "construcción, mejoramiento, reposición, ampliación y conservación de caminos y sus obras complementarias" y no tienen aplicación retroactiva frente a obras ya realizadas. Por lo tanto los criterios y recomendaciones técnicas contemplados en el Manual de Carreteras de 1997, la Norma Chilena NCH2032/2 y el Instructivo de Barreras de Seguridad dicen relación, necesariamente con obras nuevas y sus criterios y recomendaciones técnicas no pueden considerarse obligatorias frente a obras realizadas con anterioridad a su entrada en vigencia". Corte de Apelaciones de Santiago, sentencia de 14 de julio de 2010, rol No 804-2008, caratulada "Combeau Trillat René Ernesto con Rutas del Pacífico S.A. y Estado de Chile”, redacción del abogado integrante señor José Luis Borgoño Torrealba.

${ }^{33}$ Haciendo referencia expresa a "Normas Chilenas" (N Ch-INN), véase, por ej.: "Bases de licitación Red Vial Litoral Central”, del Ministerio de Obras Públicas, 2000, p. 176 (2.10.5.2); "Bases de licitación de la concesión conexión vial Melipilla-Camino de la fruta", del Ministerio de Obras Públicas, 2010, p. 221; "Bases de licitación Ruta 66-Camino de la fruta”, del Ministerio de Obras Públicas, 2010, p. 288; "Bases de licitación del Camino Internacional Ruta 60 Ch", del Ministerio de Obras Públicas, 2001, p. 182, 183; "Bases de licitación de la concesión vial autopistas de la región de Antofagasta”, del Ministerio de Obras Públicas, 2009, p. 256; “Bases de licitación de la concesión internacional Sistema Norte-Sur”, del Ministerio de Obras Públicas, 2000, p. 227 (aguas), 228 (riles); "Bases de licitación de la concesión internacional Sistema Oriente-Poniente", del Ministerio de Obras Públicas, s/d, p. 198; "Bases de licitación de la concesión Sistema Américo Vespucio Sur, Ruta 78”, del Ministerio de Obras Públicas, 2001, p. 205, 230; "Bases de licitación de la concesión Ruta 5, tramo TemucoRío Bueno", del Ministerio de Obras Públicas, 1997, p. 85, 93, 94; "Bases de licitación de la concesión Ruta 5, tramo Talca-Chillán”, del Ministerio de Obras Públicas, s/d, p. 72; "Bases de licitación de la concesión Ruta 5, tramo Santiago-Talca y acceso sur a Santiago", del Ministerio de Obras Públicas, 1998, p. 152, 153, 161; "Bases de licitación de la concesión Ruta 5, tramo Santiago-Los Vilos", del Ministerio de Obras Públicas, 1996, p. 85; "Bases de licitación de la concesión Ruta 5, tramo Río Bueno-Pto. Montt”, del Ministerio de Obras Públicas, 1997, p. 113, 119; "Bases de licitación de la concesión Ruta 5, tramo Pto. Montt-Pargua”, del Ministerio de Obras Públicas, 2009, 
Chilena en materia de aguas": Nch 1.333 de 1978, y, en menor medida, a normas sobre residuos industriales líquidos y ruido).

\section{GRADO DE DILIGENCIA QUE SE EXIGE AL CONCESIONARIO DE OBRAS VIALES EN EL CUMPLIMIENTO DE LA OBLIGACIÓN DE SEGURIDAD}

Nuestra normativa exige al concesionario vial una especial diligencia en el cumplimiento de la obligación de seguridad que tiene respecto de los usuarios $^{34}$.

$\mathrm{Al}$ efecto, y como se ha visto, la "Ley de concesiones de obras públicas" le obliga a facilitar el servicio "en condiciones de absoluta normalidad, suprimiendo las causas que originen molestias, incomodidades, inconvenienteso peligrosidad a los usuarios de las obras" [artículo $23 \mathrm{~N}^{\circ} 2$ letra a)] $]^{35}$; así como "velar por la perfecta aplicación de las normas y reglamentos sobre uso y conservación de las obras concesionadas" (artículo 24 LCOP.).

En base a lo anterior aparece entonces que el concesionario deberá cumplir con una esmerada diligencia la obligación de seguridad analizada, habiéndose destacado así que los "estrictos términos" con que la ley ordena la exigencia de normalidad no se limitan a requerir una "normalidad común o mera normalidad, sino que, 'absoluta normalidad', esto es, en sentido literal, aserción general dicha por la ley en tono de seguridad y magisterio" lo que implica que las rutas concesionadas han de otorgar al conductor vehicular "márgenes de seguridad en términos de absoluta normalidad" 36 , suprimiendo "cualquier obstáculo o alteración que impida el desplazamiento seguro de los

p. 236; "Bases de licitación de la concesión Ruta 5, tramo Los Vilos-La Serena", del Ministerio de Obras Públicas, 1996, p. 81; "Bases de licitación de la concesión Ruta 5, tramo Collipulli-Temuco", del Ministerio de Obras Públicas, 1997, p. 112; "Bases de licitación de la concesión Ruta 5, tramo Chillán-Collipulli”, del Ministerio de Obras Públicas, 1996, p. 94, 103; "Bases de licitación de la concesión Ruta 5, tramo VallenarCaldera”, del Ministerio de Obras Públicas, 2008, p. 245, entre otras.

${ }^{34}$ Expresión utilizada en sentencia de 31 de marzo de 2009, dictada por doña Susana Rodríguez Muñoz, juez titular del $25^{\circ}$ Juzgado Civil de Santiago, en causa rol No C-14324-2005, caratulada "Camposano Carvajal Paola con Sociedad Concesionaria Autopista del Bosque y Araus Vallebuena Sandra”, confirmada por Corte de Apelaciones de Santiago, sentencia de 4 de marzo de 2010, rol No 3979-2009, y por Corte Suprema, sentencia de 22 de septiembre de 2010, rol No 2762-2010.

${ }^{35}$ La norma agrega que ello es "salvo que la adopción de medidas que alteren la normalidad del servicio obedezcan a razones de seguridad o de urgente reparación”.

${ }^{36}$ Corte de Apelaciones de Valparaíso, sentencia de 16 de septiembre de 2010, rol No 77-2010, caratulada "Avilés Sepúlveda María con Sociedad Concesionaria Rutas del Pacífico S.A.”, redacción del abogado integrante señor Juan Carlos Cárcamo Olmos. 
vehiculos ${ }^{\prime 37}$. Inclusive más, en alguna sentencia se ha llegado a sostener la vigencia de una "obligación de resultado consistente en prestar servicios en un marco de seguridad para los usuarios" 38 .

Cabe hacer presente en este punto que nuestro artículo $23 \mathrm{LCOP}$. aparece claramente inspirado en el artículo 27 de la Ley N ${ }^{\circ}$ 8/1972 española (de 10 de mayo de ese año), sobre construcción, conservación y explotación de autopistas en régimen de concesión, el cual, con una redacción muy cercana, ${ }^{39}$ establece las obligaciones a que está sujeto el concesionario durante la fase de explotación ${ }^{40}$, concluyéndose mayoritariamente en tal país que dicha regla consagra una obligación de seguridad, general y permanente para el concesionario de autopistas respecto de los usuarios de las mismas y que se traduce -con independencia de la naturaleza jurídica, contractual o extra-

${ }^{37}$ Corte de Apelaciones de San Miguel, sentencia de 8 de junio de 2010, rol No 272-2010, caratulada “Ortega Bustamante Ángel con Autopista Central”, redacción del abogado integrante señor Manuel Hazbún Comandari.

${ }^{38}$ Sentencia de 26 de noviembre de 2010, dictada por doña Mariangel Cabrera Rabié, juez titular del Juzgado de Letras de Mariquina, en causa rol No C-16281-2010, caratulada "Ebner O. Constantino con Ruta de Los Ríos Sociedad Concesionaria S.A.", confirmada por Corte de Apelaciones de Valdivia, sentencia de 6 de junio de 2011, rol No 118-2011, redacción del abogado integrante señor Juan Carlos Vidal Etcheverry.

${ }^{39}$ La Ley $\mathrm{N}^{\circ} 8 / 1972$, de 10 de mayo, establece, en el capítulo VII referido a las Obligaciones del Concesionario: Artículo 27: "El régimen jurídico durante la fase de explotación en las concesiones de construcción, conservación y explotación, así como en las de conservación y explotación, será el siguiente: $1^{\circ}$ El concesionario deberá conservar la vía, sus accesos, señalización y servicios reglamentarios en perfectas condiciones de utilización. $2^{\circ}$ La continuidad en la prestación del servicio le obligará, especialmente, a:/ a) Facilitarlo en condiciones de absoluta normalidad, suprimiendo las causas que originen molestias, incomodidades, inconvenientes o peligrosidad a los usuarios de la vía, salvo que la adopción de medidas obedezca a razones de seguridad o de urgente reparación./b) Limitar las explotaciones de las áreas de servicio de forma que no interfieran la libre y normal circulación./ c) Prestarlo ininterrumpidamente durante las 24 horas del dia, salvo supuestos excepcionales debidos a caso fortuito o fuerza mayor, en cuyo caso deberá adoptar las medidas de emergencia que el Ministerio de Obras Públicas le imponga para lograr la reanudación inmediata del servicio y sin derecho a indemnización alguna. $3^{\circ}$ Podrá contratar, en la forma que los pliegos de la concesión establezcan, la gestión de los servicios complementarios comprendidos en las áreas de servicio. $4^{\circ}$ El estado se reserva sus derechos sobre los conceptos que actualmente integran la Renta de Petróleos. La concesión de estaciones de servicio en las áreas de la autopista se regirá por sus normas especificas".

${ }^{40} \mathrm{Un}$ completo panorama acerca de los distintos criterios jurisprudenciales, se encuentra en: Reglero Campos, Fernando, La responsabilidad civil del concesionario de autopistas, en Aranzadi Civil, 15-22 (1999), III, pp. 2335-2364; y Cabanillas SÁNCHEZ, Antonio, La responsabilidad civil por los daños sufridos por los usuarios de autopistas de peaje en la jurisprudencia, en Revista de Derecho Patrimonial, 9 (2002) 2, pp. 91-101. 
contractual, que se le asigne a la responsabilidad respectiva- en un estándar de conducta más exigente y riguroso que aquél que podría reclamársele por aplicación de las normas de derecho común ${ }^{41}$.

Volviendo a la regulación nacional, a las exigencias legales mencionadas se une lo dispuesto en el artículo 62 RLCOP. donde aun con mayor amplitud y estrictez se le exige al concesionario "adoptar, durante la concesión, to das las medidas para evitar daños a terceros y al personal que trabaja en la obra", agregando luego que "igualmente deberá tomar todas las precauciones para evitar daños a la propiedad de terceros y al medio ambiente durante la concesión de la obra".

Se trata de una cláusula muy amplia y severa. Al efecto, no está limitada a la fase de explotación (como las exigencias impuestas en el artículo 23 LCOP.) sino que rige en general durante la concesión. Además no tipifica las medidas o precauciones que están obligados a adoptar o tomar los concesionarios: éstas son todas aquellas que permitan alcanzar como resultado el evitar los mencionados daños durante la concesión.

Sobre el particular cabe traer a colación que, con una redacción muy cercana, el artículo 184 C.Trab. impone al empleador la obligación de seguridad respecto de sus trabajadores, al disponer que "estará obligado a tomar todas las medidas necesarias para proteger eficazmente la vida y salud de los trabajadores, manteniendo las condiciones adecuadas de higiene y seguridad en las faenas, como también los implementos necesarios para prevenir accidentes $y$ enfermedades profesionales"; entendiendo nuestros tribunales que esta regla consagra "el sentido más amplio de protección" "2 lo que implica -para un amplio sector jurisprudencial- que el empleador responderá hasta de culpa levísima en el cumplimiento de esta obligación de seguridad respecto de sus trabajadores ${ }^{43}$.

${ }^{41} \mathrm{Y}$, al efecto, Reglero Campos, Fernando, cit. (n. 40), p. 2342, ha señalado incluso que la responsabilidad del concesionario, es "más rigurosa que la que se exige a las diferentes Administraciones Públicas, titulares de vías abiertas"..

${ }^{42}$ Corte de Apelaciones de San Miguel, 23 de mayo de 2001, en RDJ., 98, sec. $3^{\text {a }}$, p. 103 ss.

${ }^{43}$ Así por ejemplo: Corte de Apelaciones de Santiago: 25 de noviembre de 1998, en GJ., 221 (1998), pp. 200 ss.; Corte de Apelaciones de Santiago, 30 de diciembre de 1999, rol No 3972-1998; Corte de Apelaciones de Santiago, 19 de enero de 1999, rol No 3576-1998; Corte Suprema, 27 de mayo de 1999, en RDJ., 96 (1999) 2a parte, sección $3^{\text {a }}$, pp. 89 ss.; Corte de Apelaciones de Santiago, 17 de enero de 2000, en GJ., 235 (2000), pp. 199 ss.; Corte de Apelaciones de Antofagasta, 3 de agosto de 2000, LegalPublishing $\mathrm{N}^{\circ}$ 17582; Corte Suprema, 8 de agosto de 2000, en RDJ., 97 (2000) 2a parte, sección $3^{\text {a }}$, pp. 152 ss.; Corte de Apelaciones de Santiago, 25 de octubre de 2000, en GJ., 245 (2000), pp. 233 ss.; Corte de Apelaciones de Santiago, 5 de noviembre de 2001, rol 6052-2000; Corte de Apelaciones de Concepción, 20 de mayo de 2002, en 
En todo caso, a lo dicho anteriormente en materia de concesiones se añaden otros preceptos del "Reglamento" en los cuales se impone al concesionario la obligación de "conservación de la obra en óptimas condiciones de uso", según lo exigido por las "Bases de licitación” [artículos 1 N³ letra b) y 54 letra b) RLCOP.], así como de cuidar "especialmente de mantenerlos libres de ocupantes, de no permitir alteraciones de sus limites y de no admitir depósitos de material ajeno a la concesión" (artículo $60 \mathrm{~N}^{\circ} 2$ RLCOP.), llegando a establecerse incluso que el concesionario será "siempre responsable" del cumplimiento "cabal, integro y oportuno" del contrato de concesión, de la "correcta" ejecución de los proyectos y de las obras, y del cumplimiento "de to das" las obligaciones establecidas en el contrato de concesión, sin perjuicio de las funciones de dirección y control que corresponde al Ministerio de Obras Públicas" (artículo 63).

\section{LA OBLIGACIÓN DE SEGURIDAD FRENTE A LAS HIPÓTESIS DAÑOSAS MÁS COMUNES}

En los acápites siguientes se analizará la aplicación que se le ha dado a la obligación de seguridad en la decisión de las principales hipótesis prácticas de daños que han generado juicios de responsabilidad civil en contra de los concesionarios de obras viales.

\section{Presencia de animales en las vías.}

La amplia mayoría de los juicios indemnizatorios planteados en esta materia derivan de accidentes producidos por la presencia de animales en vías concesionadas, y en ellos a su vez se constata una muy marcada tendencia a condenar a los concesionarios.

Para arribar a dicha conclusión se sostiene recurrentemente que esas situaciones representan una infracción a la obligación de seguridad que tienen respecto a los usuarios, y ello ya sea que los juicios respectivos se hayan planteado por responsabilidad extracontractual de derecho común (en sede

GJ., 270 (2002), pp. 160 ss. (citando a su vez fallo de la Corte Suprema publicado en RDJ., 96 (1999) 2a parte, sección 3a , pp. 89 ss.); Corte de Apelaciones de Concepción, 10 de julio de 2002, confirmada por Corte Suprema en fallo de 20 de enero de 2003, ambas en FM., 506 (2003), pp. 5267 ss.; Corte de Apelaciones de Concepción, 27 de septiembre de 2002, rol N ${ }^{\circ}$ 1958-2001; Corte de Apelaciones de Santiago, 29 de agosto de 2003, rol 7245-2002; Corte de Apelaciones de Chillán, 19 de julio de 2007, rol N 44-2007, LegalPublishing $\mathrm{N}^{\circ}$ 36679; Corte de Apelaciones de San Miguel, 16 de agosto de 2007, rol N 123-2007; Corte de Apelaciones de Punta Arenas, 24 de agosto de 2007 , rol N ${ }^{\circ} 17-2007$, entre otros. 
civil ${ }^{44}$ o como acciones civiles deducidas ante los Juzgados de Policía Local como derivadas de infracción a la Ley $\mathrm{N}^{\circ}$ 18.290: Del Tránsito ${ }^{45}$ ), por falta

\footnotetext{
${ }^{44}$ Así, por ejemplo: Sentencia de 30 de diciembre de 2002, dictada por doña Pilar Aguayo Pino, juez titular del $8^{\circ}$ Juzgado Civil de Santiago, en causa rol 5574-2001, caratulada "Fernández Fornés Francisco Javier con Sociedad Concesionaria de Carreteras Talca Chillán S.A. y Fisco de Chile”, transcrita en Klenner, Arturo, cit. (n. 6), pp. 141-166, confirmada por la Corte de Apelaciones de Santiago, en sentencia de 6 de septiembre de 2007, rol No 1677-2003; Sentencia de 25 de julio de 2006, dictada por doña Jenny Book Reyes, juez titular del $7^{\circ}$ Juzgado Civil de Santiago, en causa rol 3421-2003, caratulada "Borjes Muñoz, María Teresa con Sociedad Concesionaria Autopista del Sol S.A.”, transcrita en KLENNER, Arturo, cit. (n. 6), pp. 215-234, la cual fue revocada por falta de prueba de los daños por la Corte de Apelaciones de Santiago, en sentencia de 26 de agosto de 2009, rol No 9275-2006, redacción del Ministro señor Muñoz Pardo; sentencia de 31 de marzo de 2009, dictada por doña Susana Rodríguez Muñoz, juez titular del $25^{\circ}$ Juzgado Civil de Santiago, en causa rol No C-14324-2005, caratulada "Camposano Carvajal Paola con Sociedad Concesionaria Autopista del Bosque y Araus Vallebuena Sandra”, confirmada por Corte de Apelaciones de Santiago, en sentencia de 4 de marzo de 2010, rol No 3979-2009 y siendo declarados luego inadmisibles los recursos de casación en su contra por Corte Suprema, en sentencia de 22 de septiembre de 2010, rol No 2762-2010; Corte de Apelaciones de Santiago, sentencia de 6 de agosto de 2009, rol No 10202-2006, caratulada "Reyes Silva Francisco y otro con Zegers León Eugenio y otro”, redacción del Ministro señor Cornelio Villarroel Ramírez; Corte de Apelaciones de Santiago, sentencia de 30 de marzo de 2010, rol No 3311-2009, caratulada "González Vergara Jorge con Ruta 5 Tramo TalcaChillán”, redacción del abogado integrante señor Francisco Tapia Guerrero; sentencia de 14 de octubre de 2009, dictada por doña Inelie Durán Madina, juez titular del $2^{\circ}$ Juzgado Civil de Santiago, en causa rol No C-17544-2007, caratulada "Gómez Zúniga Julio con Autopista del sol y Fisco de Chile", confirmada por Corte de Apelaciones de Santiago, en sentencia de 5 de noviembre de 2010, rol No 8162-2009, redacción del abogado integrante señor Enrique Pérez Levetzow; Corte Suprema, sentencia de 28 de enero 2010, rol No 6919-2008, caratulada "Canales Valenzuela María con Ruta 5 Tramo Talca Chillán S.A.”, redacción del Ministro señor Héctor Carreño; Corte de Apelaciones de Valparaíso, sentencia de 16 de septiembre de 2010, rol No 77-2010, caratulada "Avilés Sepúlveda María con Sociedad Concesionaria Rutas del Pacífico S.A.", redacción del abogado integrante señor Juan Carlos Cárcamo Olmos.

${ }^{45}$ Corte de Apelaciones de Valdivia, sentencia de 6 de diciembre de 2003, rol No 119.288-03, caratulada "Contra Torres Calderón, Claudio y otros, Dte.: Carabineros de Purranque”, redacción del Ministro señor Juan Ignacio Correa Rosado; y sentencia de 20 de febrero de 2007, dictada por don Héctor Pérez Oñate, Juez de Policía Local de Río Negro, en causa rol № 36801, confirmada por Corte de Apelaciones de Valdivia, en sentencia de 1 de octubre de 2008, rol No 198-2007, redacción de la Ministra Sra. Emma Díaz Yévenes.
} 
de servicio ${ }^{46}$ o por responsabilidad contractual (en sede civil ${ }^{47} \mathrm{o}$ ante los Juzgados de Policía Local como acciones civiles derivadas de infracción a la Ley de Protección de los derechos de los consumidore ${ }^{48}$ ), caso en el cual se precisa que la aludida obligación de seguridad tendría naturaleza legal y contractual ${ }^{49}$. En estas situaciones se estimará que el incumplimiento de la obligación de seguridad analizada representará, respectivamente, culpa aquiliana, falta de servicio o culpa contractual.

Para arribar a esta conclusión se ha insistido reiteradamente en que, la eventual responsabilidad que conforme a sus propios estatutos pudiera afectar a los propietarios o tenedores de los animales o a los dueños u ocupantes de los predios con acceso a las vías públicas ${ }^{50}$, no excluye la que le asiste a los concesionarios de obras viales por infracción a su mencionada obligación de seguridad respecto de los usuarios ${ }^{51}$, y que en este ámbito implica "mantener la ruta libre de animales sueltos en la vía que impidan el tránsito vebicular

${ }^{46}$ Sentencia de 30 de abril de 2009, dictada por doña María Paula Merino Verdugo, juez titular del $4^{\circ}$ Juzgado Civil de Santiago, en causa rol No C-5148-2006, caratulada “González Vergara Jorge con Ruta 5 Tramo Talca Chillán”; confirmada por Corte de Apelaciones de Santiago, en sentencia de 30 de marzo de 2010, rol № 3311-2009, aun cuando ésta entiende que debe responder por responsabilidad extracontractual de derecho común.

${ }^{47}$ Corte de Apelaciones de San Miguel, sentencia de 8 de junio de 2010, rol No 272-2010, caratulada "Ortega Bustamante Ángel con Autopista Central”, redacción del abogado integrante señor Manuel Hazbún Comandari.

${ }^{48}$ Sentencia de 12 de diciembre de 2006, dictada por doña María Loreto Astorga Moreno, Juez de Policía Local de Ovalle, en causa rol No 4892-2006, caratulada "Forttes Iribarren, Claudia Paz con Sociedad Concesionaria Elqui S.A.", confirmada por Corte de Apelaciones de La Serena, en sentencia de 19 de abril de 2007, rol No 22-2007.

${ }^{49}$ Así, por ejemplo, expresamente: sentencia de 30 de diciembre de 2002, dictada por doña Pilar Aguayo Pino, juez titular del $8^{\circ}$ Juzgado Civil de Santiago, en causa rol 5574-2001, caratulada "Fernández Fornés Francisco Javier con Sociedad Concesionaria de Carreteras Talca Chillán S.A. y Fisco de Chile”, transcrita en KLEnner, Arturo, cit. (n.6), pp. 141-166, confirmada por la Corte de Apelaciones de Santiago, en sentencia de 6 de septiembre de 2007, rol N 1677-2003.

${ }^{50}$ En lo infraccional en base a lo dispuesto en el artículo $165 \mathrm{~N}^{\circ} 11$ de la Ley $\mathrm{N}^{\circ}$ 18.290, Ley de Tránsito y en materia civil extracontractual en base a lo dispuesto en los artículos 2326 y 2327 del Código Civil.

${ }^{51}$ De configurarse la responsabilidad civil de los demás sujetos pasivos antes mencionados se ha dicho que existiría "una concurrencia de causas" y "pluralidad de responsables". Corte Suprema, sentencia de 28 de enero 2010, rol No 6919-2008, caratulada "Canales Valenzuela María con Ruta 5 Tramo Talca Chillán S.A.", redacción a cargo del Ministro señor Héctor Carreño, caso en el cual el damnificado tendría el derecho de accionar optativamente contra la Concesionaria. Sentencia de 12 de diciembre de 2006, dictada por doña María Loreto Astorga Moreno, Juez de Policía Local de Ovalle, 
o puedan colisionar con los vebiculos", vigilarla permanentemente "a fin de detectar y evitar situaciones de riesgo o accidentes que involucren riesgos a los usuarios y sus bienes" 53 , realizar "todas las obras, adoptar todas las prevenciones $y$ tomar todos los resguardos que las especiales características del camino o autopista y su entorno requieran" ${ }^{n 4}, \mathrm{y}$ todo ello de manera permanente y en cada lugar de la obra, desde que, por el contrato de concesión, el concesionario "tiene el derecho a cobrar a los usuarios una tarifa por cada kilómetro transitado 55 ".

Como se señala ilustrativamente en una sentencia: aun cuando se estime que existe responsabilidad del dueño del animal o de su cuidador, e incluso de los dueños de los predios colindantes que eventualmente no hayan mantenido sus cercos en buen estado, "es dable presumir que si la [sociedad concesionaria] demandada hubiese adoptado las ya mentadas medidas preventivas de seguridad y control el caballo no habria ingresado a la carretera, habria sido retirado con la prontitud necesaria o se hubiese intervenido el tránsito de manera tal que el accidente no ocurriese y, por ende, no se habría producido el daño, consecuencia directa de su omisión negligente" 56 .

Más enfáticamente aun, la Corte de Apelaciones de Santiago ha señalado

en causa rol No 4892-2006, caratulada "Forttes Iribarren, Claudia Paz con Sociedad Concesionaria Elqui S.A.").

${ }^{52}$ Sentencia de 30 de diciembre de 2002, dictada por doña Pilar Aguayo Pino, juez titular del $8^{\circ}$ Juzgado Civil de Santiago, en causa rol 5574-2001, caratulada "Fernández Fornés Francisco Javier con Sociedad Concesionaria de Carreteras Talca Chillán S.A. y Fisco de Chile", transcrita en KLENnER, Arturo, cit. (n. 6), pp. 141-166, confirmada por la Corte de Apelaciones de Santiago, en sentencia de 6 de septiembre de 2007, rol 1677-2003, que cita los artículos 23 y 34 [hoy 35] LCOP. y el contrato de concesión.

${ }^{53}$ Corte de Apelaciones de Valdivia, sentencia de 6 de diciembre de 2003, rol No 119288-03, caratulada "Contra Torres Calderón, Claudio y otros, Dte.: Carabineros de Purranque”, redacción del Ministro señor Juan Ignacio Correa Rosado.

${ }^{54}$ Corte de Apelaciones de Santiago, sentencia de 18 de agosto de 2008, rol No 11.965-2004, caratulada "Concha Soffia, Cristián con Sociedad Concesionaria Rutas del Pacífico S.A.”, redacción del abogado integrante señor Enrique Pérez Levetzow, señalándose además en tal caso que, atendida la regulación de la obra, "es obligación de la concesionaria instalar no solamente barreras que impidan el acceso a la vía de animales que puedan entorpecer la libre circulación vehicular de los usuarios, sino que además realizar todas aquellas obras necesarias para el cumplimiento oportuno de las obligaciones de otorgar seguridad a dichos usuarios que se sirvan de tal concesión".

${ }^{55}$ Corte de Apelaciones de Santiago, sentencia de 5 de noviembre de 2010, rol No 8162-2009, caratulada “Gómez Zúniga Julio con Autopista del Sol y Fisco de Chile”, redacción del abogado integrante señor Enrique Pérez Levetzow.

${ }^{56}$ Sentencia de 25 de julio de 2006, dictada por doña Jenny Book Reyes, juez titular del $7^{\circ}$ Juzgado Civil de Santiago, en causa rol No 3421-2003, caratulada "Borjes Muñoz, María Teresa con Sociedad Concesionaria Autopista del Sol S.A.”, transcrita en Klenner, Arturo, cit. (n. 6), pp. 215-234. Esta sentencia fue luego revocada pero por no haberse probado la existencia de los daños, cuestión diversa al punto por la que se le 
que "colinda con lo absurdo la afirmación de la concesionaria demandada en cuanto a que no es dueña ni tiene a su cuidado animal alguno, puesto que su responsabilidad no emana del dominio de los animales sino de no haber tenido el cuidado debido para impedir el ingreso de los mismos" ${ }^{57}$.

Las sentencias en sentido contrario son contadas ${ }^{58}$, habiéndose impuesto condenas inclusive en casos en que se acreditó una pronta y rápida alerta y llegada al lugar donde merodeaba el animal ${ }^{59}$ o la realización previa de patrullajes y el auxilio al accidentado llegando en forma casi inmediata al lugar del accidente; todo ello en el entendido que dichas medidas fueron insuficientes en concreto para cumplir con los "deberes de cuidado elementales que contempla la ley, considerando por cierto, que las rutas concesionadas han de otorgan al conductor vehicular márgenes de seguridad en términos de absoluta normalidad"60.

Lo dicho anteriormente ha llevado a que incluso se haya llegado a condenar a concesionarios de obras viales sin haberse probado que conforme a sus respectivas bases de licitación hubiesen estado obligados a cerrar la ruta en el lugar por donde pudieron ingresar los animales, recordándose además que en base al artículo 1546 CC. el contrato de concesión no sólo obligaba a lo

ha citado: en Corte de Apelaciones de Santiago, sentencia de 26 de agosto de 2009, rol No 9275-2006, redacción del Ministro señor Muñoz Pardo.

${ }^{57}$ Corte de Apelaciones de Santiago, sentencia de 5 de noviembre de 2010, rol No 8162-2009, caratulada "Gómez Zúniga Julio con Autopista del Sol y Fisco de Chile", redacción del abogado integrante señor Enrique Pérez Levetzow.

${ }^{58}$ En tal sentido: sentencia de 3 de enero de 2003, dictada por don Jorge Eduardo Gamboa Cornu, juez titular del Juzgado de Policía Local de Los Vilos , querellante y demandante civil "María Angélica Sepúlveda de la Cerda con Sociedad Autopista del Aconcagua S.A.”, en la cual no aparece indicado el rol de la causa (rechazando querella infraccional y demanda civil atendido que en el caso concreto la Concesionaria no estaba obligada al "mantenimiento de los cierres o linderos, aledaños a la ruta concesionada", en tanto que la "Legislación General Civil" "solo hace responsable a los dueños de tales animales"); y sentencia de 3 de enero de 2003, dictada también por don Jorge Eduardo Gamboa Cornu, juez titular del Juzgado de Policía Local de Los Vilos, querellante y demandante civil Juan Ignacio González Guridi con Sociedad Autopista del Aconcagua S.A., rol 556-2002-2 (rechazando querella infraccional y demanda civil atendido atendido a que "ninguna disposición legal o contractual se ha acompañado que permita concluir que la empresa concesionada está obligada a mantener siempre y en todo lugar o en toda circunstancia la vía despejada" en tanto que la Ley de Tránsito y el artículo 2326 CC. sólo hacen responsables a los dueños de los animales).

${ }^{59}$ Corte de Apelaciones de San Miguel, sentencia de 8 de junio de 2010, rol No 272-2010, caratulada “Ortega Bustamante Ángel con Autopista Central”, redacción del abogado integrante señor Manuel Hazbún Comandari.

${ }^{60}$ Corte de Apelaciones de Valparaíso, sentencia de 16 de septiembre de 2010, rol No 77-2010, caratulada "Avilés Sepúlveda María con Sociedad Concesionaria Rutas del Pacífico S.A.”, redacción del abogado integrante señor Juan Carlos Cárcamo Olmos. 
que en él se había expresado, sino que también a todo aquello que emanaba "de la naturaleza de la obligación", lo que en la especie habría implicado la obligación de "instalar esas barreras de contención, asi como también realizar cualquier obra que permita dar cumplimiento a la obligación de brindar seguridad a los usuarios" ${ }^{61}$. Existen en todo caso pronunciamientos en contrario sobre esta particular problemática ${ }^{62}$.

\section{Otros obstáculos en la ruta.}

Se han deducido también demandas por una variedad de otras situaciones de obstáculos en las rutas (como rocas, tierra, neumáticos, restos de carga o árboles) contra los cuales han impactado los usuarios o, aun sin que ello se produzca, han motivado maniobras evasivas que a su vez han terminado en accidentes lesivos para ellos (lo que incluso se ha planteado por la presencia indebida de peatones en la calzada).

$\mathrm{Al}$ efecto, si bien existen algunas sentencias que rechazan estas acciones, lo cierto es que lo hacen principalmente por no haberse probado la existencia de los obstáculos o que éstos hayan sido la causa del accidente ${ }^{63}$, siendo ex-

\footnotetext{
${ }^{61}$ Sentencia de 30 de abril de 2009, dictada por doña María Paula Merino Verdugo, juez titular del $4^{\circ}$ Juzgado Civil de Santiago, en causa rol No C-5148-2006, caratulada "González Vergara Jorge con Ruta 5 Tramo Talca Chillán", confirmada por Corte de Apelaciones de Santiago, en sentencia de 30 de marzo de 2010, rol No 3311-2009, redacción del abogado integrante señor Francisco Tapia Guerrero, trayendo a colación incluso lo dispuesto en el "Manual de Carreteras", en su punto 3.802.3 que obligaba a contar con "barreras laterales" en atención a las "particulares características del tramo en que ocurrió el accidente y su entorno"..

${ }^{62}$ Eximiendo por esta circunstancia: Corte de Apelaciones de Santiago, sentencia de 14 de octubre de 2009, rol No 2277-2010, caratulada "Crocco Villarroel Juan Alejandro con Sociedad Concesionaria AMB S.A.”, redacción del Ministro señor Jorge Dahm. En el mismo sentido: Corte de Apelaciones de Concepción, sentencia de 18 de marzo de 2011, rol № 1420-2010, caratulada "Muñoz Cuevas Alejandro Marcelo y otra con Camino de la Madera Sociedad Concesionaria S.A.”, redacción del abogado integrante señor Hugo Tapia Elorza, confirmada por Corte Suprema, sentencia de 2 de junio de 2011, rol No 3336-2011, señalando que no se acreditó "con los instrumentos pertinentes" que regían la respectiva concesión "si en concreto la concesionaria se obligó a cerrar la ruta de modo de evitar el ingreso de animales o incluso peatones a la calzada destinada al tránsito vehicular".

${ }^{63}$ Corte de Apelaciones de Concepción, sentencia de 29 de julio de 2004, rol N².761-2003, caratulada "Galdames Morales Héctor, con Camino de la Madera Concesionaria S.A.”, redacción del Ministro señor Diego Simpértigue Limare, donde se señaló que "no se encuentra probado el derrumbe que señala el actor y menos que como consecuencia de él se haya dañado el automóvil del demandante". Cabe hacer presente que por sentencia de 28 de septiembre de 2005, se rechazó recurso de casación en el fondo interpuesto en su contra, rol Corte Suprema N³.780-04.
} 
cepcionales los casos en que se analiza el comportamiento de la concesionaria para exculparla ${ }^{64}$.

La tendencia general es a condenarlas y ello ha ocurrido ya se haya accionado por responsabilidad extracontractual de derecho común (en sede civil $^{65} \mathrm{o}$ como acciones civiles deducidas ante los Juzgados de Policía Local como derivadas de infracción a la Ley 18.290, Ley de Tránsito ${ }^{66}$ ) como por responsabilidad contractual en sede civil ${ }^{67}$, situaciones en las que se ha estimado incumplida la obligación de seguridad analizada y configurada consecuencialmente culpa aquiliana o culpa contractual, en su caso.

En estas situaciones se ha dicho que no se ha prestado el servicio en condiciones de absoluta normalidad pues han existido causas que originan molestias, incomodidades, inconvenientes y en definitiva peligrosidad a los usuarios de las obras [artículo $23 \mathrm{~N}^{\circ} 2$ letra a)], y ello sin perjuicio de constituir también infracción a la obligación de conservar las obras, sus accesos y servicios en condiciones normales de utilización (artículo $23 \mathrm{~N}^{\circ} 2$ ) y a la de mantener los terrenos y bienes afectos a la concesión libres de ocupantes y de no admitir depósito de material ajeno a la concesión (artículo $60 \mathrm{~N}^{\circ} 2 \mathrm{RLCOP}$ ).

En tal sentido se ha resuelto, por ejemplo, que "la empresa demandada no

${ }^{64}$ En este último sentido: Corte de Apelaciones de Puerto Montt, sentencia de 30 de diciembre de 2010, rol No 103-2010, caratulada "Querellante: Johanna del Carmen Gallardo Paredes y otro contra Sociedad Concesionaria de los Lagos S.A.”, redacción del Ministro señor Leopoldo Vera Muñoz, en que se señaló que "no es posible inferir que la causa del accidente y los daños producidos por la caída de una rueda desde un camión no identificado que circulaba por la ruta 5 Sur, en las circunstancias descritas, sea imputable o de responsabilidad de la demandada, empresa Sociedad Concesionaria Los Lagos S.A., sociedad que en este caso no ha incumplido su obligación de vigilancia permanente de la ruta a su cargo y, en consecuencia, por no existir ningún tipo de infracción, debe desestimarse la querella y demanda de indemnización de perjuicios".

${ }^{65}$ Sentencia de 3 de julio de 2008, dictada por don Jorge Mena Soto, juez titular del $28^{\circ}$ Juzgado Civil de Santiago, en causa rol No C-8115-2004, caratulada "Barros Aldunate Juan Patricio con Sociedad Concesionaria Rutas del Pacífico S.A.”; confirmada por Corte de Apelaciones de Santiago, en sentencia de 3 de diciembre de 2009, rol No 622-2009; Sentencia de 31 de marzo de 2009, dictada por doña Susana Rodríguez Muñoz, juez titular del $25^{\circ}$ Juzgado Civil de Santiago, en causa rol № C-4417-2006, caratulada "Catalán Menares, Mario Edgardo con Sociedad Concesionaria Autopista del Sol S.A.”.

${ }^{66}$ Corte de Apelaciones de Valparaíso, sentencia de 15 de mayo de 2009, rol No 239-2009, caratulada "Querellado demandado: Sociedad Concesionaria Autopista Los Andes S.A. Rep. Luis Miguel de Pablo Ruiz. Querellante y demandante civil: Paola Manterola Bustamante", redacción del abogado integrante señor Julio Reyes Madariaga.

${ }^{67}$ Corte de Apelaciones de Santiago, sentencia de 9 de junio de 2009, rol No 9196 2006, caratulada “Moya Acevedo Ángel Gabriel y otros con Autopista del Maipo S.A.", redacción del abogado integrante señor Enrique Pérez Levetzow 
cumplió oportuna y adecuadamente con su obligación de mantener el camino en condiciones normales de servicio", máxime "cuanto dispuso del tiempo necesario y prudente-dos horas-para eliminar el obstáculo que impedia el flujo normal del tránsito vehicular y sólo reaccionó una vez producido el accidente" 68 , que el accidente deriva de la "inexistencia de medidas adecuadas de seguridad frente al ingreso de peatones" ${ }^{69} \mathrm{e}$ inclusive ante el accidente producido por "un fierro de aproximadamente cuatro metros de largo que se encontraba sobre el pavimento en medio del camino" se llegó a sostener que el concesionario de obras viales debió adoptar las "medidas preventivaspertinentes, o sea, vigilancia adecuada al momento de ingresar a la autopista camiones con carga que no vaya bien instalada en tales vehiculos" y ello por cuanto, en concepto del tribunal, "habitualmente las empresas transportistas cuyos camiones circulan a lo largo de nuestro pais, no adoptan el debido cuidado con la carga que transportan"70.

Cabe añadir en este punto que también se ha condenado a concesionarios de obras viales por la específica hipótesis de responsabilidad tipificada en el artículo 96 de la Ley No 18.290: Del Tránsito (antiguo artículo 102) cuando a consecuencia de trabajos ejecutados en las vías públicas quedaron "piedras de regular tamaño en medio de la calzada" que originaron un accidente ${ }^{71}$.

\section{Deficiente conservación de las obras viales concesionadas.}

En otros casos ventilados en nuestra práctica se han acogido demandas fundadas en la deficiente conservación de las obras viales concesionadas.

$\mathrm{Al}$ efecto, así ocurrió probado que en la producción del accidente tuvo

${ }^{68}$ Sentencia de 3 de julio de 2008, dictada por don Jorge Mena Soto, juez titular del 28 Juzgado Civil de Santiago, en causa rol No C-8115-2004, caratulada "Barros Aldunate Juan Patricio con Sociedad Concesionaria Rutas del Pacífico S.A.”, confirmada por Corte de Apelaciones de Santiago, sentencia de 3 de diciembre de 2009, rol No 622-2009.

${ }^{69}$ Sentencia de 31 de marzo de 2009, dictada por doña Susana Rodríguez Muñoz, juez titular del $25^{\circ}$ Juzgado Civil de Santiago, en causa rol No C-4417-2006, caratulada "Catalán Menares, Mario Edgardo con Sociedad Concesionaria Autopista del Sol S.A.", donde se reprocha además "la inadecuada protección en el puente del canal Tuzano, las que, en caso de haber existido como tal, habrian evitado las consecuencias" que los demandantes invocan en su demanda.

${ }^{70}$ Corte de Apelaciones de Santiago, sentencia de 9 de junio de 2009, rol № 91962006, caratulada “Moya Acevedo Ángel Gabriel y otros con Autopista del Maipo S.A.”, redacción del abogado integrante señor Enrique Pérez Levetzow.

${ }^{71}$ Corte de Apelaciones de Valparaíso, sentencia de 15 de mayo de 2009, rol No 239-2009, caratulada "Querellado demandado: Sociedad Concesionaria Autopista Los Andes S.A. Rep. Luis Miguel de Pablo Ruiz. Querellante y demandante civil: Paola Manterola Bustamante", redacción del abogado integrante señor Julio Reyes Madariaga. 
injerencia la inadecuada iluminación de la vía ${ }^{72}$ o la acumulación de agua en una depresión de la calzada por falta de mantención de los sistemas de evacuación ${ }^{73}$, o por la presencia de un hoyo existente en el bandejón central dejado allí para colocar árboles, por la empresa encargada y por donde cayó un peatón ${ }^{74}$, o por la existencia de un forado en la reja que separaba ambas vías de la autopista, y que era utilizado constantemente por los habitantes del sector para cruzar la autopista, "a raiz de la lejanía y dificultades para acceder a la pasarela que se ubica a unos 300 metros", hecho que fue considerado "la causa directa e inmediata de la muerte de los padres de los actores, puesto que de no existir dicho paso, el accidente por atropello no habria ocurrido"75.

Las condenas en estos casos tienen también como fundamento la obligación de facilitar el servicio en condiciones de absoluta normalidad suprimiendo las causas que originan molestias, incomodidades, inconvenientes y en definitiva peligrosidad a los usuarios de las obras [artículo $23 \mathrm{~N}^{\circ} 2$, letra a) LCOP.], de "conservar las obras, sus accesos, señalización y servicios en condiciones normales de utilización" (artículo $23 \mathrm{~N}^{\circ} 1 \mathrm{LCOP}$. lo que guarda a su vez relación con lo dispuesto en el artículo 18 inciso $1^{\circ}$ parte final del Decreto con fuerza de ley $\mathrm{N}^{\circ}$ 850, del Ministerio de Obras Públicas, de 25 de febrero de 1998, en orden a que la "conservación y reparación de las obras entregadas en concesión" le corresponde al concesionario). Y todo ello sin perjuicio que en numerosas

${ }^{72}$ Sentencia de 14 de octubre de 2009, dictada por doña Inelie Durán Madina, juez titular del Segundo Juzgado Civil de Santiago, en causa rol No C-17544-2007, caratulada "Gómez Zúniga Julio con Autopista del sol y Fisco de Chile", confirmada por Corte de Apelaciones de Santiago, en sentencia de 5 de noviembre de 2010, rol No 81622009, redacción del abogado integrante señor Enrique Pérez Levetzow. En este caso, la falta de iluminación concurre con la inadecuada señalización en un caso de presencia de animales en la calzada.

${ }^{73}$ Sentencia de 26 de noviembre de 2010, dictada por doña Mariangel Cabrera Rabié, juez titular del Juzgado de Letras de Mariquina, en causa rol No C-16281-2010, caratulada "Ebner O. Constantino con Ruta de Los Ríos Sociedad Concesionaria S.A.", confimándose la condena por la Corte de Apelaciones de Valdivia, en sentencia de 6 de junio de 2011, rol No 118-2011, redacción del abogado integrante señor Juan Carlos Vidal Etcheverry.

${ }^{74}$ Corte de Apelaciones de San Miguel, sentencia de 25 de enero de 2008, rol No 963-2007, caratulada “Ortiz Tamayo Margarita con Autopista Central”, redacción del Ministro señor José Ismael Contreras Pérez

${ }^{75}$ Sentencia de 26 de diciembre de 2007, dictada por don Humberto Provoste Bachmann, juez titular del $26^{\circ}$ Juzgado Civil de Santiago, en causa rol No C-9768-2005, caratulada "González Melo Eliana del Carmen y otros con Sociedad Concesionaria Autopista del Sol”, confirmada por Corte de Apelaciones de Santiago, sentencia de 7 de diciembre de 2009, rol No 730-2008. 
Bases de Licitación aparece consagrada expresamente la obligación del concesionario de responder por ciertas deficiencias viales como baches ${ }^{76}$.

$\mathrm{Y}$ en esta línea las sentencias condenatorias dejan establecido que en estas hipótesis el concesionario condenado incumplió con ello "su deber de conservar la obra en condiciones normales de utilización y de suprimir las causas que originen peligrosidad para los usuarios" adecuada conservación a la ruta, lo cual constituye una obligación contenida en la Ley de Concesiones de Obras Públicas"78. Además, cabe mencionar que las condenas se han dictado en los diversos regímenes en que las acciones respectivas han sido planteadas. Así las hay tanto en juicios de responsabilidad extracontractual de derecho común ${ }^{79}$, como por responsabilidad contractual $^{80}$, situaciones en las que se ha estimado que el incumplimiento de la obligación de seguridad analizada configura consecuencialmente culpa aquiliana o culpa contractual, en su caso.

Muy excepcionalmente se absuelve a una concesionaria establecido que si bien en la producción del accidente contribuyó la existencia de escarcha en la calzada, había sin embargo advertido suficientemente a los usuarios por medio de avisos radiales contratados, sobre la necesidad de manejar con

${ }^{76}$ En tal sentido, por ejemplo: "Bases de licitación de la concesión Ruta 60 Ch", MOP, 2001 (cláusula 1.8.15); “Concesión de Ruta Concepción-Cabrero”, MOP, 2009 (1.8.16); "Concesión Ruta 5, Tramo La Serena-Vallenar”, MOP, 2009 (2.4.3.5.1); "Concesión Autopistas Región de Antofagasta” (1.8.15); entre otras.

${ }^{77}$ Sentencia de 26 de noviembre de 2010, dictada por doña Mariangel Cabrera Rabié, juez titular del Juzgado de Letras de Mariquina, en causa rol No C-16281-2010, caratulada "Ebner O. Constantino con Ruta de Los Ríos Sociedad Concesionaria S.A.".

${ }^{78}$ Corte de Apelaciones de Valdivia, sentencia de 6 de junio de 2011, rol No 118 2011, caratulada "Ebner O. Constantino con Ruta de Los Ríos Sociedad Concesionaria S.A.”, redacción del abogado integrante señor Juan Carlos Vidal Etcheverry.

${ }^{79}$ Sentencia de 26 de diciembre de 2007, dictada por don Humberto Provoste Bachmann, juez titular del $26^{\circ}$ Juzgado Civil de Santiago, en causa rol № C-9768-2005, caratulada "González Melo Eliana del Carmen y otros con Sociedad Concesionaria Autopista del Sol", confirmada por Corte de Apelaciones de Santiago, sentencia de 7 de diciembre de 2009, rol No 730-2008; Sentencia de 14 de octubre de 2009, dictada por doña Inelie Durán Madina, juez titular del Segundo Juzgado Civil de Santiago, en causa rol No C-17544-2007, caratulada "Gómez Zúniga Julio con Autopista del sol y Fisco de Chile”, confirmada por Corte de Apelaciones de Santiago, en sentencia de 5 de noviembre de 2010, rol No 8162-2009, redacción del abogado integrante señor Enrique Pérez Levetzow; Corte de Apelaciones de Valdivia, sentencia de 6 de junio de 2011, rol No 118-2011, caratulada "Ebner O. Constantino con Ruta de Los Ríos Sociedad Concesionaria S.A.”, redacción del abogado integrante señor Juan Carlos Vidal Etcheverry.

${ }^{80}$ Sentencia de 26 de noviembre de 2010, dictada por doña Mariangel Cabrera Rabié, juez titular del Juzgado de Letras de Mariquina, en causa rol № C-16281-2010, caratulada “Ebner O. Constantino con Ruta de Los Ríos Sociedad Concesionaria S.A.”. 
precaución ya que se presentarían precipitaciones de agua nieve y escarcha en la calzada ${ }^{81}$, entendiéndose además, por la Corte de Apelaciones que revisó el caso, que se habría configurado en la especie un caso fortuito ${ }^{82}$.

\section{Problemas de diseño y señalización.}

Por problemas de diseño vial y en base a las reglas de la responsabilidad extracontractual de derecho común se condenó a concesionarios de obras viales por la inadecuada protección en un puente, la que de existir habría evitado las consecuencias que los demandantes invocan en su demanda ${ }^{83}$, así como por la ausencia de defensas camineras que impidieran el ingreso de caballares a la calzada señalándose al efecto que el artículo 23 LCOP. "guarda correspondencia con la pauta normativa y técnica entregada por la Dirección de Vialidad en el Manual de Carreteras, que establece en el punto 3.802 .3 que Sea en curva o en recta se debe considerar la instalación de defensas; si existe una posibilidad de accidente o si la altura del terraplén o en el terreno abrupto provocan una sensación de inseguridad en el conductor'. Destaca: 'Los sectores que pueden presentar condiciones adversas de neblina, hielo o nieve o sectores de camino con tránsito de alta velocidad o elevado volumen, justifican la consideración de defensas" ${ }^{84}$.

En estos casos se sostuvo que es "inequivoco que en la sociedad demandada recae el deber de seguridad en la explotación y conservación de las rutas concesionadas", lo que en la especie implicaba la implementación de barreras laterales consideradas las particulares características del tramo en que ocurrió el accidente y su entorno ${ }^{85}$ o que la falta de implementos de seguridad

${ }^{81}$ Sentencia de 31 de octubre de 2006, dictada por don Rolando Christian Díaz Coloma, Juez Subrogante del Juzgado de Letras de Puerto Varas, en causa rol $\mathrm{N}^{\circ}$ 32.674, caratulada "Rehbein Monsalve, Hernán Sociedad Concesionarias Los Lagos Limitada”.

${ }^{82}$ Corte de Apelaciones de Puerto Montt, sentencia de 20 de julio de 2007, rol $\mathrm{N}^{\circ}$ 941-2006, caratulada "Rehbein Monsalve, Hernán Sociedad con Concesionarias Los Lagos Limitada”, redacción del abogado integrante Jorge Ebensperger Brito.

${ }^{83}$ Sentencia de 31 de marzo de 2009, dictada por doña Susana Rodríguez Muñoz, juez titular del $25^{\circ}$ Juzgado Civil de Santiago, en causa rol No C-4417-2006, caratulada "Catalán Menares, Mario Edgardo con Sociedad Concesionaria Autopista del Sol S.A.”.

${ }^{84}$ Corte Suprema, sentencia de 28 de enero 2010, rol No 6919-2008, caratulada “Canales Valenzuela María con Ruta 5 Tramo Talca Chillán S.A.”, redacción a cargo del Ministro señor Héctor Carreño; confirmando lo resuelto por Corte de Apelaciones de Santiago, sentencia de 21 de agosto de 2008, rol No 2330-2005, redacción del abogado integrante señor Enrique Pérez Levetzow.

${ }^{85}$ Corte Suprema, sentencia de 28 de enero 2010, rol No 6919-2008, caratulada "Canales Valenzuela María con Ruta 5 Tramo Talca Chillán S.A.", redacción a cargo del Ministro señor Héctor Carreño; confirmando lo resuelto por Corte de Apelaciones 
adecuados en la zona de ocurrencia del accidente constituye una "infracción a un estándar de cuidado y entrega de adecuados servicios a los usuarios de la vía concesionada" 86 .

Por otro lado también ha sido condenada una concesionaria por responsabilidad extracontractual de derecho común por la inadecuada señalización cuando esa circunstancia fue la causa que un automóvil atropellara a una menor que salía de una escuela causándole la muerte ${ }^{87}$, y en otra oportunidad en base a la particular figura de responsabilidad civil contemplada en la Ley $\mathrm{N}^{\circ}$ 18.290: Del Tránsito (artículo 102, hoy 96) se condenó a una concesionaria y a su contratista considerando que no se señalizaron suficientemente las labores que se realizaban en la vía ${ }^{88}$.

Cabe recordar en este punto que la obligación legal de conservación alcanza a la señalización de la obra, la que deberá estar en condiciones normales de utilización (artículo $23 \mathrm{~N}^{\circ} 1$ LCOP.), y ello sin perjuicio a las referencias expresas a esta obligación que usualmente se contienen en las respectivas bases de licitación en donde se suele señalar que la concesionaria debe "procurar la seguridad del tránsito para los usuarios, debiendo proveer, colocar y mantener letreros y señales de peligro, diurno y nocturno, durante todo el periodo de las faenas; proveer personal de señaleros día y noche, como también los equipos y ayudapara emergencias" ${ }^{\prime \prime 9}$, todo lo anterior, ajustándose a la normativa estatal

de Santiago, sentencia de 21 de agosto de 2008, rol № 2330-2005, redacción del abogado integrante señor Enrique Pérez Levetzow.

${ }^{86}$ Sentencia de 31 de marzo de 2009, dictada por doña Susana Rodríguez Muñoz, juez titular del $25^{\circ}$ Juzgado Civil de Santiago, en causa rol No C-4417-2006, caratulada "Catalán Menares, Mario Edgardo con Sociedad Concesionaria Autopista del Sol S.A."

${ }^{87}$ Sentencia de 3 de marzo de 2008, dictada por don Alvaro Saavedra Sepúlveda, juez titular del 3er. Juzgado de Talca, en causa rol No 4661-2004, caratulada "Toledo Acuña, Luis Armando con Sociedad Talca Chillán Sociedad Concesionaria S.A.”

${ }^{88}$ Sentencia de 29 de septiembre de 2005, dictada por doña Rocío Pérez Gamboa, Juez Suplente del $25^{\circ}$ Juzgado Civil de Santiago, en causa rol N ${ }^{\circ}$ 5778-2002, caratulada "Calderón Reyes, Elisa con Ruta del Pacífico S.A.", transcrita en Klenner, Arturo, cit. (n. 6), pp. 181-205; confirmada por Corte de Apelaciones de Santiago, 18 de marzo de 2009, rol N ${ }^{\circ}$ 10.839-2005, redacción de la Ministro señora Gloria Ana Chevesich Ruiz.

${ }^{89}$ En tal sentido, por ejemplo: "Bases de licitación de la concesión Ruta 5- Tramo Chillán-Collipulli”, MOP, 1996 (cláusula 1.7.2.8); "Concesión de la Ruta 5 Tramo Vallenar-Caldera”, MOP, 2008 (1.9.2.8.); "Concesión dee la Ruta Concepción-Cabrero", MOP, 2009 (2.4.4.3); "Concesión de la Autopistas Región de Antofagasta”, MOP, 2009 (1.9.2.8); "Concesión de la Ruta 5-Tramo Pto. Montt-Pargua”, MOP, 2009 (1.9.2.8); entre otras. 
sobre señalización en vías públicas, y del mismo modo, velar por el estado de la señalización durante la ejecución de la concesión ${ }^{90}$.

En todo caso, se exculpará a la concesionaria demandada si se establece que no fue posible desvirtuar la presunción de responsabilidad que afectaba a quien conducía bajo la influencia del alcohol de ser esa la causa del accidente "y no la alegada falta de señalización en el camino que, a lo más, pudo ser una causa concurrente" ${ }^{\prime \prime}$.

\section{Daños por pedradas lanzadas a vehiculos en marcha.}

Un problema complejo lo constituyen las demandas indemnizatorias por lesiones causadas a ocupantes de vehículos que han sido apedreados en instantes en que circulaban por vías concesionadas.

$\mathrm{Al}$ efecto existen soluciones encontradas.

Se ha condenado a concesionarias establecido que se incumplió la obligación de mantener y conservar la pasarela desde donde fue lanzada una roca de gran peso, al no contar con las "medidas de seguridad necesarias para el funcionamiento de la obra en su integridad" ; o porque "ha cumplido sólo parcialmente con las exigencias de seguridad al no contemplar un protocolo especial que establezca como evento, no la erradicación del vandalismo, sino su prevención en la ruta concesionada, y al actuar tardiamente con la implementación de seguridad al colocar una reja en la pasarela o paso bajo nivel en donde se arrojó la piedra, con posterioridad a los hechos en estudio"93.

Sin embargo, en sentido inverso se pronunció la Corte de Apelaciones de Santiago, sosteniendo que "no puede predicarse negligencia ante un acontecimiento imprevisible y/o inevitable" que además implica una acción delictiva y respecto del cual la concesionaria no estaba en situación de impedir o evitar;

${ }^{90}$ En tal sentido, por ejemplo: "Bases de licitación de la concesión Ruta 5-Talca, Acceso sur Santiago", MOP, 1998 (cláusula 8.2.3.1); "Concesión de la Ruta 60 Ch", MOP, 2001 (2.3.1.11.1); “Concesión Santiago-Melipilla, Camino de la Fruta”, MOP, 2010 (2.2.12.1); entre otras.

${ }^{91}$ Corte Suprema, sentencia de 30 de marzo de 2009, rol No 3437-2007, caratulada “Demandante: Opazo Ruiz César y otra Demandado: Fisco de Chile y otros", redacción a cargo del Ministro señor Adalis Oyarzún Miranda.

${ }^{92}$ Sentencia de 6 de septiembre de 2007, dictada por doña Inelie Durán Madina, juez titular del Segundo Juzgado Civil de Santiago, en causa rol No C-1486-2003, caratulada "Valck Gladys con Fisco de Chile y otra".

${ }^{93}$ Sentencia de 31 de julio de 2009, dictada por don Javier Torres Vera, juez titular del 27º Juzgado Civil de Santiago, en causa rol No C-10375-2004, caratulada "Bossay Pisano, Paula y Varas Boetsch, Miguel con Fisco de Chile y Sociedad Concesionaria Rutas del Pacífico"; confirmada por la Corte de Apelaciones de Santiago, en sentencia de 9 de noviembre de 2010, rol No 6523-2009, redacción de la Ministro señora Dobra Lusic Nadal. 
máxime cuando los deberes de ella "conciernen nada más a la circulación por la vía pública, es decir, al tránsito sobre el suelo pavimentado, pues asi debe colegirse de las voces "camino" que emplea el punto II. 9.12 de las Bases de licitación y "baches" del título III capítulo 13 del Reglamento" ${ }^{\text {"94. }}$

Cabe hacer presente finalmente que la preocupación por estas situaciones ha sido tal que la Ley $\mathrm{N}^{\circ} 20.149$ de 23 de enero de 2007 agregó un artículo $196 \mathrm{H}$ a la Ley $\mathrm{N}^{\circ}$ 18.290: Del Tránsito, el cual sanciona penalmente el atentado a pedradas o de otra forma similar a vehículos en marcha.

\section{Accidentes en eventos naturales adversos.}

Dos casos podemos mencionar sobre el particular. Ambos dicen relación con accidentes producidos en el marco de fuertes lluvias que afectaron a la Región del Bío Bío el año 2006, y en los cuales las concesionarias han sido condenadas por responsabilidad extracontractual de derecho común rechazándose la configuración en la especie de un caso fortuito.

En uno de ellos se dio por establecido que la existencia de barro y lodo en la calzada fue la única causa de que el conductor perdiera el control del vehículo que conducía y se estrellara contra el muro debiendo responder la concesionaria pues "faltó negligente y culpablemente al deber de seguridad que le imponian las Bases Técnicas de su concesión" las cuales le obligaban a una serie de acciones como "construir muros de contención que solucionaran los problemas de drenaje, escurrimiento y derrumbes; en segundo término, patrullar permanentemente el camino para detectar estas causas de accidente y avisar a los usuarios conforme a la señalización de tránsito correspondiente, y en tercer término, despejar la zona del derrumbe no sólo del lodo sino también auxiliando y retirando vehiculos, todas obligaciones incumplidas" 95 .

En el otro caso, en actual tramitación, se condenó a la concesionaria por la caída de un vehículo a las aguas de un estero producto del desmoronamiento de la calzada producido por el aumento de su caudal generando la muerte de su conductor. Para arribar a esa conclusión se sostuvo que aunque el desplome de la calzada haya sido solo momentos antes que cruzara la víctima,

${ }^{94}$ Corte de Apelaciones de Santiago, sentencia de 29 de enero de 2010, rol No 5243 2007, caratulada "Herraz Díaz Nancy con Autopista del Sol”, redacción del Ministro señor Carlos Cerda Fernández

${ }^{95}$ Sentencia de 8 de mayo de 2008, dictada por Carola Paz Rivas Rojas, juez titular del 3er. Juzgado de Letras en lo Civil de Concepción, en causa rol N ${ }^{\circ}$ 5296-2006, caratulada "Orellana Hidalgo con Camino de la Madera", confirmado por la Corte de Apelaciones de Concepción en sentencia de 18 de agosto de 2009, en causa rol 1174-2008, redacción de la Ministro señora Rosa Patricia Mackay Foigelman y siendo rechazados los recursos de casación en el fondo por la Corte Suprema en sentencia de 31 de enero de 2012, rol N 7313-2009, redacción de la Ministra Rosa Egnem Saldías. 
"ello debió ser previsto por la sociedad demandada, porque la causa de la caída de aquélla, no se produjo en ese mismo momento, sino es anterior y ha debido mediar entre ellas un periodo considerable, pues se ha iniciado con el aumento del caudal, la incapacidad de la obra para evacuarla, luego el socavamiento de los terraplenes, socavamiento que la sociedad reconoce pudo haberlo detectado su sistema de vigilancia y finalmente la caída de las vías de acceso al puente Batuquito", añadiendo luego que "no obsta a la conclusión anterior, el hecho acreditado en el proceso que producida la caída de la victima al socavón, llegó un vehiculo de la concesionaria con dospersonas" desde que "resulta evidente que esa llegada es en todo caso inoportuna, pues dichos funcionarios de la demandada debieron haber detectado con anterioridad el aumento del caudal, la incapacidad de evacuación de este aumento y luego el socavamiento de los terraplenes de acceso al puente". Las consideraciones anteriores llevaron a dar por establecida la culpa aquiliana de la sociedad demandada y justificaron consecuencialmente el rechazo a su alegación de caso fortuito para lo cual se tuvo presente además que el socavamiento no ha sido en modo alguno imprevisible considerando además que las precipitaciones "se prolongaban a lo menos desde el día anterior a los hechos y a las 11:30 horas del día anterior habia ocurrido un daño similar en otro puente de la concesión", consignando así que "si una persona alega que la lluvia de varios días en el sur de Chile constituye un caso fortuito no será oída", citando las palabras del Profesor Pablo Rodríguez $\mathrm{Grez}^{96}$.

\section{Conclusiones}

Hecho este análisis concluimos que:

1. La normativa y jurisprudencia chilenas reconocen que el concesionario de obras viales tiene la obligación constante y permanente de garantizar la seguridad de los usuarios en la utilización de las obras concesionadas.

2. La jurisprudencia chilena entiende que para fijar el contenido de la obligación de seguridad referida es necesario analizar no sólo exigencias legales o reglamentarias generales sino también aquéllas contenidas en una amplia normativa complementaria de diversa jerarquía a que nos hemos referido, dentro de la cual se incluyen, pacíficamente, los instrumentos regulatorios de cada obra concesionada en particular ("Bases de licitación", "Oferta técnica y económica" presentada por el adjudicatario de la concesión en la forma aprobada por el Ministerio de Obras Públicas, los "Decretos

${ }^{96}$ Sentencia de 2 de marzo de 2012, dictada por Camilo Álvarez Ordenes, juez titular del $2^{\circ}$ Juzgado de Letras en lo Civil de Concepción, en causa rol $N^{\circ} 3297-2008$, caratulada "Cabeza Muñoz con Ruta del Bosque Sociedad Concesionaria". 
supremos de adjudicación" respectivos y el "Reglamento de servicio de la obra", entre otros).

3. La normativa y jurisprudencia chilenas exigen al concesionario de obras viales una esmerada diligencia en el cumplimiento de la analizada obligación de seguridad ${ }^{97}$.

4. La mayoría de las hipótesis fácticas que han generado pleitos de responsabilidad civil en este ámbito han llevado a condenas para los concesionarios de obras viales en el entendido que representan incumplimientos de la obligación de garantizar la seguridad de los usuarios en la utilización de las obras concesionadas.

Así sucede, por regla muy general, en los accidentes producidos por la presencia de animales y otros obstáculos en las vías, por deficiente conservación de las obras viales concesionadas, por inadecuado diseño y señalización y también en los pocos casos planteados respecto de accidentes ocurridos en eventos naturales adversos, en tanto que en las hipótesis de daños por pedradas lanzadas a vehículos en circulación se han emitido sentencias contrapuestas.

5. La jurisprudencia chilena entiende vigente y analiza de manera sustancialmente análoga el cumplimiento de la obligación de seguridad referida en los distintos regímenes en base a los cuales se han resuelto las demandas de responsabilidad civil en este ámbito.

Ello se constató al analizar acciones por responsabilidad civil extracontractual de derecho común (en sede civil o ante Juzgados de Policía Local como derivada de una infracción a la Ley de Tránsito), en responsabilidad contractual (en sede civil o ante los Juzgados de Policía Local como derivada de una infracción a la Ley de protección de los derechos de los consumidores) y por falta de servicio ${ }^{98}$.

En todos estos casos se comprobó que el incumplimiento de la obligación de seguridad analizada ha servido para fundar las condenas a los concesionarios desde que él se considera determinante para configurar culpa aquiliana, falta de servicio o culpa contractual, en su caso.

De este modo por esta vía se produce un notable factor de acercamiento

${ }^{97}$ Cabe recordar en todo caso, que precaviendo el impacto económico que pueden generar para los concesionarios sentencias adversas en este ámbito, nuestra normativa los obliga a "tomar pólizas de seguro que cubran la responsabilidad civil por daños a terceros” (artículo 36 RLCOP.).

${ }^{98}$ Teóricamente sería irrelevante analizar el cumplimento de la obligación de seguridad en los casos en que se sostenga que rige en la materia una responsabilidad legal u objetiva por imposición directa de lo que establece el artículo 35 LCOP. Sin embargo, en nuestra jurisprudencia reciente tal solución parece abandonada. 
entre estos diversos regímenes a la hora de solucionar casos prácticos en esta materia ${ }^{99}$.

\section{Bibliografía}

Águila Rojas, Enrique Adolfo, De la responsabilidad extracontractual por daños en las carreteras concesionadas (Memoria de Prueba para optar al Grado de Licenciado en Ciencias Jurídicas, Universidad Bolivariana (Santiago, 2006 [pero 2007]).

Cabanillas SÁnChez, Antonio, La responsabilidad civil por los daños sufridos por los usuarios de autopistas de peaje en la jurisprudencia, en Revista de Derecho Patrimonial, 9 (2002) 2.

Diez SCHWERTER, José Luis, Reparación y prevención de daños derivados de deficiencias viales en Chile: panorama normativo y jurisprudencial, en Revista de Derecho de la Universidad de Concepción, 221-222 (2007 [pero 2008]) = GUZMÁN BRITO, Alejandro (editor científico), Estudios de Derecho Civil (Santiago, LegalPublishing, 2008), III.

Domper Rodríguez, María de la Luz, Concesiones de obras públicas: lo que hemos avanzado y cuánto ha ganado Chile, en LARroulet, Cristián - Domper, María de la Luz (coordinadores), Concesiones: agenda para el 2020 (Santiago, Libertad y Desarrollo, 2009).

IbarRa Coronado, Rafael, La ley de concesiones de obras públicas chilena en el tiempo, en International Law. Revista Colombiana de Derecho Internacional, 19 (2011).

KLENNER, Arturo, Indemnización de perjuicios por daños personales o patrimoniales en el tránsito en vías concesionadas (Santiago, Aremi, 2007).

Rabat Celis, Fernando José, Responsabilidad civil de las sociedades concesionarias de obras públicas fiscales respecto del usuario de las mismas, en Estudios jurídicos en homenaje a los profesores Fernando Fueyo Laneri, Avelino León Hurtado, Francisco Merino Scheibing, Fernando Mujica Bezanilla, Hugo Rosende Subiabre (Santiago, Ediciones Universidad del Desarrollo, 2007).

Reglero Campos, Fernando, La responsabilidad civil del concesionario de autopistas, en Aranzadi Civil, 15-22 (1999), III.

ROMÁN CORDERo, Cristián, La responsabilidad del Estado por los daños sufridos por el usuario de una carretera concesionada, por inactividad administrativa en ejercicio de sus facultades de inspección y vigilancia, en Fernández Ruiz, Jorge - SANTIAGo SÁNCHEZ, Javier (coordinadores), Contencioso administrativo. Culturas y sistemas jurídicos comparados (México, 2007)[consultable también en Internet en: www. bibliojuridica.org/libros/5/2445/19.pdf].

ROMÁn CORDero, Cristián, Responsabilidad de la Administración del Estado y de su concesionario vial, frente al usuario lesionado, en Actas de XXXV Jornadas Chilenas de Derecho Público. El Derecho público chileno ante la globalización (Valparaíso, Edeval, 2006) II.

Viñuela Hojas, Mauricio, La concesión de obras públicas en Chile: ¿Privatización de

${ }^{99}$ Las disparidades operativas entre ellos quedan así limitadas especialmente, en su caso, a cuestiones de competencia, procedimiento, apreciación de la prueba y prescripción. Al respecto véase: Diez Schwerter, José Luis, cit. (n. 6), pp. 79-81. 
la responsabilidad del Estado en la empresa concesionaria? en Cuadernos de Extensión Jurídica, 7 (Santiago, Universidad de los Andes, 2003).

Viñuela Hojas, Mauricio, La responsabilidad por falta de servicio en el contexto del régimen de concesiones viales vigentes en Chile, en Ius Publicum, 7 (Santiago, Universidad San Tomás, 2001). 